\title{
Solar Tracking System with New Hybrid Control in Energy Production Optimization from Photovoltaic Conversion for Polish Climatic Conditions
}

\author{
Grażyna Frydrychowicz-Jastrzębska and Artur Bugała *
}

Citation: Frydrychowicz-Jastrzębska, G.; Bugała, A. Solar Tracking System with New Hybrid Control in Energy Production Optimization from Photovoltaic Conversion for Polish Climatic Conditions. Energies 2021, 14, 2938. https://doi.org/10.3390/ en14102938

Academic Editor: Ana Gracia Amillo

Received: 25 March 2021

Accepted: 15 May 2021

Published: 19 May 2021

Publisher's Note: MDPI stays neutral with regard to jurisdictional claims in published maps and institutional affiliations.

Copyright: (c) 2021 by the authors. Licensee MDPI, Basel, Switzerland. This article is an open access article distributed under the terms and conditions of the Creative Commons Attribution (CC BY) license (https:// creativecommons.org/licenses/by/ $4.0 /)$.
Faculty of Control, Robotics and Electrical Engineering, Poznan University of Technology, 60-965 Poznań, Poland; grazyna.jastrzebska@put.poznan.pl

* Correspondence: artur.bugala@put.poznan.pl

\begin{abstract}
This paper presents a comparison of the 24-month production of electricity and momentary power by two photovoltaic systems with a nominal power of $1000 \mathrm{~W}_{\mathrm{p}}$ each. The analyzed systems are connected to the power grid and operate independently: a fixed system with optimal all-year-round angular positioning and an astronomical-sensor-controlled dual-axis tracking system. The systems under consideration consist of PV modules with a unit electrical power of $200 \mathrm{~W}_{\mathrm{p}}$, and the production technology of those modules is the same. The tested systems were located on the building rooftop of the Faculty of Control, Robotics and Electrical Engineering of the Poznan University of Technology in Poland (Central Poland, 52 $24.4152^{\prime}$ N, $16^{\circ} 55.7958^{\prime}$ E) at a height of $30 \mathrm{~m}$ above ground level. The measurements take into account the consumption of electricity by the actuators of the dual-axis positioning system. Increases in the produced electricity by $35.6 \%$ and $44.7 \%$ were observed for local climatic conditions during the first and second measuring years, respectively, when comparing the use of the dual-axis tracking system with the use of fixed units. Results show that the analyzed region of central Poland, represented by the city of Poznań, creates favorable climatic conditions for the use of astronomical-sensor spatial positioning systems for photovoltaic modules, also in the case of a significant share of diffuse solar radiation in the global value. These results may make the planning of solar tracking investments easier and help with the estimate calculations of the total investment return period and operational costs.
\end{abstract}

Keywords: sun tracking system; photovoltaic conversion; energy gain; spatial optimization; renewable energy source

\section{Introduction \\ 1.1. Maximum Power Point Tracking Systems}

One way to increase the efficiency of photovoltaic conversion is the provision of the optimal spatial orientation of the solar radiation receiver. This is a function of both the angle of inclination $\beta$ of the receiver to the Earth's surface and the angle of azimuth which determines the deviation from the local meridian in relation to the southern direction [1].

The optimal angle of inclination of the receiver changes quite considerably each day of the year and each hour of the day as the angle of the sun changes. Most PV systems are fixed structures or structures placed manually on a seasonal or hourly basis along one axis. Because of the difficulties involved in the continuous adjustment of the position of the receiver to the changing angle of sun declination $\delta$ (described by Cooper's rule, and having a different value each day of the year and each hour of the day), the mean value of angle $\beta$ is frequently set for the given time period, e.g., for the entire year or for summer or winter months [1]. However, such a solution is inconvenient logistically. An additional aspect of this issue is the instability, or even unpredictability, of the weather conditions, even when monitoring is ensured for many years. It is difficult to synchronize the position of receivers with the current state, especially in the case of more powerful installations. A 
number of simplified procedures are used; however, they do not provide fully satisfying results with regards to guaranteeing the optimal performance of the systems.

The impact of the angle of azimuth on energy gain is not as significant as the impact of the angle of inclination of the receiver to the ground. This pertains mainly to the morning and evening hours; however, it should not be ignored in calculations. In the case of fixed solutions, the southern direction is preferred [1].

It is unrealistic to precisely establish and, in particular, implement the optimal spatial orientation for the solar energy receiver by changing its position manually at each moment of time. Such requirements may be met as a result of the use of a tracker. In order to achieve maximum energy gains, it is necessary to apply a tracking system with a maximum power point tracking option. Tracking systems are provided with different drive options, among which one should mention active tracking, passive tracking, semipassive tracking, manual tracking, and chronological tracking [2].

Other research [2] presents a comprehensive review of such solutions and their potential in the context of solar energy production. The authors characterized the available structures, taking into account the drive systems as well as their application capacities. As their studies show, the dual-axis tracking systems are the most popular systems (used in almost $80 \%$ of applications). The most frequently used type of tracking drive is the active tracking module $(76.42 \%)$. Such solutions also give the best results. Similarly, the authors of another study [3] conducted an insightful analysis, evaluation, and categorization of MPPT solutions with different degrees of complexity and efficiency. They also precisely specified the future developmental trends.

In one publication [4], the methods of tracking in the PV systems (MPPT) under normal and partial shadow conditions (PSC) were discussed. The MPPT methods were classified as based on artificial intelligence, also taking into account the intelligent MPPT with the configurable technology of field-programmable gate array (FPGA), and evolutionary programming techniques.

One synthetic paper [5] contains a comparative analysis of MPPT techniques, whereby the authors focused mainly on numerical methods. In addition to a high level of precision, these methods guarantee the flexibility of application.

Based on analysis of the technical documentation and bibliographic reports [1,6,7], it was found that the use of single-axis systems requires an increase in investment by about $10-15 \%$ in comparison with fixed systems. On the other hand, the energy gain in dual-axis solutions is higher by $20-30 \%$. A similar comparison between the investment outlays of dual-axis and fixed solutions demonstrated an increase of $15-20 \%$, with an increased energy gain of about $30-40 \%$. In the case of many locations and diverse tracker drives, the aforementioned gain exceeds these values significantly $[1,7,8]$.

As well as the aforementioned energy gain, solar "tracking" has a positive effect on the performance of PV systems:

1. During the movement of the mounting frame with modules, dust and dirt are removed. This limits losses and provides protection against the "hot spot" effect, which is a result of uncontrolled shading [9]. A fragment of the "hot spot" area may reach a temperature of over $250^{\circ} \mathrm{C}$, which usually leads to damaging of cells and, in an extreme case, its self-ignition.

2. The operation of the dual-axis solar tracker eliminates losses resulting from the nonperpendicular incidence of solar radiation, which are referred to as angular losses.

3. The PV systems on rotary mounting frames also have another positive effect as a result of movement relative to the air; this contributes to a reduction in losses that are the consequence of an increase in temperature.

4. With regards to the operation of a tracking structure near the maximum power point $(M P P)$, the performance of the inverter coupled with it is increased.

On the other hand, the most important drawbacks include the necessity to provide necessary space, which can be as much as $50 \%$ larger for such solutions when compared to fixed ones, and the higher cost of the tracking structure in combination with the drive. 
The overriding objective of the projects that involve "tracking" is to maintain the accuracy of positioning with a margin of error not exceeding $1^{\circ}$ and to maximize the electrical energy gain in the set interval, with a simultaneous limitation of its consumption. Hence, some of the authors warn against excessive losses resulting from the consumption of energy by the drive system $[8,10,11]$.

The authors of another publication [8] suggest resignation from "solar tracking" during cloudy days even in the summer season, as it is ineffective and causes additional energy losses related to the nonproductive powering of the tracker's drive system. They recommend the positioning of the receiver parallel to the ground. In newer solutions, this option is taken into account automatically [12]. In [8], the authors also specify the methodology of estimation of the theoretical profitability threshold for solar tracking.

The efficiency of the single-axis solar tracker was studied by Yousif for a location in Malta [13]. The author compared the $360 \mathrm{~W}_{\mathrm{p}}$ single-axis PV system with a fixed solution, the power of which was unfortunately different, so the systems were not fully compatible. The comparative monitoring of their operation covered a period of 12 months. In the case of the single-axis solar tracking, a stable performance factor was maintained despite the high-speed winds that occurred at that time. However, the fixed system operated with lower efficiency during the summertime. The author has a critical opinion about the control system of the tracker because of the energy losses caused by the necessity to use a pilot PV module with a double area (higher power).

J.Y. Muhammad and his team also demonstrated in their review paper from the year 2019 [11] that the solar tracker is more efficient in comparison with the solar fixed system and that the dual-axis tracking system is more efficient than the single-axis system. The authors, however, do not recommend the use of solar trackers with tracking in the case of a low-power installation because of the relatively high power consumption of the drive systems, which ranges between 2 and 3\% of the energy increase ensured by the solar energy tracking equipment, which in the case of a low-power installation constitutes a significant deficit.

Thus, in general, irrespective of the location of the tested objects and the time period of the tests as well as the method of control of the tracker structure, it must be concluded that dual-axis tracking solutions have an energy advantage over similar fixed and single-axis solutions. It is only possible to speculate on the level of these gains.

These observations are confirmed by the authors of another paper [2], who also focussed on dual-axis tracking systems. They highly valued their capacities, whereby they estimated a $35-43 \%$ increase in the efficiency of the system when compared to fixed solutions.

In their considerations, the authors of a further publication [8] demonstrated a slightly wider range of possibilities to increase the system efficiency from $20 \%$ to even $50 \%$ when compared to fixed solutions with the receiver in the optimal position. The numerical and experimental verification confirmed these considerations based on the isotropic sky model.

The valuable results of research on the positioning of polycrystalline, monocrystalline, and amorphous silicon modules were presented by H. Zsiborács et al. in 2019 [14]. The authors examined the positioning features of selected photovoltaic modules installed in dual-axis tracking systems relative to the focus points of concentrator photovoltaic modules under real meteorological conditions in Keszthely (Hungary) in the summers of 2017, 2018, and 2019 on fourteen days. The authors stated that performance insensitivity thresholds of photovoltaic modules depend on the direction of the changes, emphasizing that inclination changes towards northwest, southwest, southeast, and northeast lead to significant changes in the values of the recorded parameters.

The comparison of two innovative trackers, sensorless (with a tracking error of $0.43^{\circ}$ ) and sensor (with a tracking error of $0.14^{\circ}$ ), taking into account the seasonality, was the subject of [15]. The authors stated that the application of a south-facing sensor solar tracker increases the average daily energy by $27.7 \%, 32.5 \%, 37.3 \%, 42.7 \%$, and $35.22 \%$ in winter, spring, fall, summer, and one year, respectively. In the case of a sensorless tracker, these values were equal to $19.1 \%, 22.4 \%, 26.1 \%, 30.2 \%$, and $24.59 \%$, respectively. 
In [16], the results of measurements for two identical photovoltaic systems with a rated power of $7.8 \mathrm{~kW}$ are presented. One of them had a fixed position and the angle of inclination to the ground equal to the latitude value, the other was equipped with a two-axis tracker. The two-axis solar tracking system made it possible to obtain $30.79 \%$ more electric energy compared to a fixed latitude tilt system. The research was conducted in the annual period from April 2010 to March 2011.

The advantage of the tracking systems provided with a control system that includes positioning on two axes seems to be unquestionable in comparison with fixed systems. This issue is also confirmed by the authors of numerous papers [1,2,8,13,17-23], who specify the energy gains that they achieved in their studies for the structures under consideration.

Particularly spectacular results were obtained in Toledo, Spain, using the Titan Tracker Si-01TC solution [7]. The studies were conducted for a period of one year, whereby the energy gains were at a level of $57 \%$ in July, 52\% in May, and even $47 \%$ in January. The described unit offers great possibilities of changes in the ranges of angles of inclination (between $1^{\circ}$ and $90^{\circ}$ ) and angles of azimuth (between $-180^{\circ}$ and $+180^{\circ}$ ).

Among many analyzed works related to these issues, the authors of only one publication came to the conclusion that the use of tracking systems does not provide any noticeable benefits. These surprising conclusions were drawn by R.G. Vieira et al. [10] after conducting tests in an area of high insolation in Brazil (Mossoró). They compared the energy gain from photovoltaic conversion in two cases, for a fixed solution and a single-axis tracker. Having conducted the operating analysis and compared the performance of the systems under consideration, it was found that an increase in the generated power in the single-axis solution is only slightly higher in reference to the fixed solution [10].

Not all of the aforementioned publications describe a case in which both systems would operate over a period of at least one year.

\subsection{Solar Radiation Detection Methods}

The proper design of the tracker's structure, including the various available tracking options, requires a multicriteria approach to solving the task at hand; the consideration of mechanical, energy, meteorological, and economic factors; and, frequently, the inclusion of mathematical models and algorithms as well as computer techniques [8,21,22,24].

In one published paper [21], Yasser M. Safan et al. proposed an innovative solution that guarantees high tracking accuracy even during adverse, particularly cloudy conditions. They developed a hybrid control strategy, which they implemented using the intelligent multiple degrees of freedom (MDOF) controller. The basis for the operation of the analyzed controller is its capacity for integration in an astronomical algorithm in an open loop and a control strategy in a closed loop. In order to simulate the control process, the MATLAB/Simulink package was used. The verification of the adopted strategy for the new solution demonstrated performance at a level of $97 \%$ for a day-long operation of the $60 \mathrm{~W}_{\mathrm{p}}$ module.

In [25], the design of an innovative solar tracking system intended for application in greenhouses was described. The developed structure of the tracker took into account the geographical location (the northeastern part of China) and the climatic conditions that correspond to this location. It was demonstrated that the energy gains in reference to the fixed system range between 20 and $25 \%$.

The test results presented in another publication [23] refer to selected locations in Nigeria. The efficiency of the inclined single-axis and dual-axis tracking surfaces was compared taking into account six tracking orientations. The preceding simulation tests were based on the Koronakis isotropic model and Perez anisotropic model. This allowed for an initial estimation of the potential and possibilities of the solar energy before final verification (System Advisor Model) and evaluation. The authors estimated the possibility of increasing the performance in relation to the fixed solution at a level of almost $32 \%$ in an extreme case. 
At the beginning of the second decade of the 21st century, solutions using lightdependent resistor (LDR) sensors gained importance. When the tracking system is subject to positioning that involves the use of the external pyramidal sensor, the selection of the dihedral angle, which determines the reciprocal position of the LDR sensors, is fundamental because of the accuracy of observation of the location of the source of radiation and the proportions between the amount of the electricity generated and the energy used for the system's own needs [26]. This ratio depends on, among other things, the degree of cloudiness. With a high accuracy of positioning on both axes, this may lead to a loss of even $10 \%$ of the electricity on an annual basis [10]. D.F. Spencer, in his book [27], presented a similar analysis regarding the reciprocal angular position of two sensory elements. The value of the dihedral angle that the author took into account for his analysis was $45^{\circ}$.

Proper functioning of the system, which is the result of accurate control, may be ensured through the precise selection of photosensitive LDR elements for both axes [28]. The practical use of this implication in single-axis solutions is shown in $[29,30]$, and the case of dual-axis solutions is shown in [31,32].

One research paper [33] presents another solution using LDR sensors. These sensors receive solar radiation. The authors of the publication presented a solar tracking module on two axes, which is based on microcontrollers. In the system under consideration, two DC motors operated by a PIC16F72 microcontroller were used in the drive. It processes the information from the LDR sensors through the internal ADC analog converter and transmits information to the IC-LM392D motor controller. The latter one controls the operation of the motors.

Other methods of detection of the perpendicularity of solar incidence were described in further papers [34-37].

In the year 2004, the vision method [38] using a CCD camera with a resolution of $768 \times 576$ pixels was used for locating the position of the sun in the sky. The structure was integrated with a heliostat system (mirror), which allowed for the concentration of solar radiation on the detection element. As a result of the comparison of the obtained image with the reference image, a differential signal was generated to implement the control process.

A.M. Brisha presented very promising test results for a location in the Mansoura state in Egypt [39]. The tests covered a period of 6 months from March to September 2017. The proposed system was based on the technology of the automatic process of dual-axis solar tracking. It operates on the principle of the real-time clock (RTC). The real-time clock system may generate a periodical signal transmitted to the processor and other elements of the computer at the right moment. According to the author's claims, the increase in the output power from the panel is $74 \%$ higher than in the case of the fixed solution. The authors of this paper are full of admiration for these achievements; however, they suggest that such spectacular performance should be confirmed for other locations and for longer testing intervals.

Muhammad E.H. Chowdhury and his team [22] promote the application of algorithms of the position of the sun that are based on mathematical description or the application of astronomical data in sensor-controlled PV systems. The proposed procedure, which uses the astronomical almanac algorithm (AAA), allows for an increase in performance by $2.1 \%$ in the case of the solar tracking system (the sensor-controlled one only) and by $13.09 \%$ in reference to the fixed system. The developed system is reliable, accurate, and cost-effective.

Various programs for the simulation of energy gain are available: PVSYST, PVGIS, and PVSOL. However, they do not ensure the real conditions, which require, for instance, the consideration of the dispersion or deflection of solar radiation.

One review publication [40] presents different solutions for trackers that are operated by means of algorithms, in the context of achievable performance. In this study, algorithms related to maximum power point tracking (MPPT) were the main focus, and the same focus is seen in [39]. Furthermore, an automatic tracking module based on a microcontroller was implemented. Its operation was tested in real time. The authors plan to use a step 
motor in their construction, which is to be connected with the advanced RISC machine (ARM) processor [40]. This solution seems to be worth attention due to its simple and energy-saving architecture.

Other literature [24] includes guidelines for the design of an intelligent PID controller. The task was performed using a simple logic algorithm that adjusts the controller parameters automatically. The controller must also be characterized by high performance and should ensure the appropriate standards in process modeling, a modern control system, and the ability to adapt at any time and in any weather conditions. This was confirmed by the verifying simulation conducted using the MATLAB/Simulink software package.

The authors of another study [41] take advantage of this package too. They distinguish the conventional methods of perturbation and observation $(\mathrm{P} \& \mathrm{O})$ and incremental conductance (IncCond), and among more advanced methods, they mention MPPT based on fuzzy logic (FL). The overview of these methods demonstrated that the static and dynamic performance of the fuzzy MPPT controller is higher than in the case of a controller based on traditional techniques.

J. Macaulay and Z. Zhou also used the perturbation and observation (P\&O) method in their research [42] and introduced their own modifications. The MPPT solution was tested. The authors managed to reduce the impact of weather conditions and oscillations. In [43], thanks to the $\mathrm{P} \& \mathrm{O}$ method, greater efficiency and accuracy were obtained. Fuzzy logic, on the other hand, was also used to study MPPT algorithms in [44].

M.H. Enany [45] and his team presented the modeling and evaluation of tracking algorithms (MPPT). These algorithms are simulated in the MATLAB/Simulink environment in order to ensure a comparison in terms of the required sensors and ease of implementation, as well as performance and dynamic response of the photovoltaic (PV) systems to changes in temperature and irradiation intensity. What is interesting is that an innovative approach to artificial intelligence, based on the adaptive neuro-fuzzy inference system (ANFIS), was also presented. This technique is distinguished by its high precision and operating speed.

In the case of some tests, the use of sensors was abandoned as has been reported, e.g., in $[46,47]$.

The precise sensorless PV module was characterized in one publication [46]. Experimental and comparative verification with a fixed system showed that as a result of the application of a tracking system, the energy gain ranges between 19.1-30.2\%, depending on the season under consideration. The solution is cost-effective and simple in operation. The tracking error is estimated by the author at $0.43^{\circ}$, and operation is independent of any interference and cloudiness.

The presented paper provides a detailed comparison between the production of electricity from photovoltaic conversion, using a previously designed and physically available dual-axis tracking system, with a control system that integrates astronomical and sensor-based positioning and a system of installed fixed PV modules, synchronized with the power grid, for an installation site located in central Poland for a 24-month period of time. The aim of this paper is also to draw attention to the possibility of increasing the efficiency of operation of photovoltaic installations and to provide an argument that there is the possibility to reduce, to a great extent, the impact of selected time, climatic, and geographical parameters through the use of solar tracking systems.

\section{Materials and Methods}

\subsection{Fixed Photovoltaic Installation}

An integral part of the fixed system is the $1000 \mathrm{~W}_{\mathrm{p}}$ photovoltaic generator $\left(5 \times 200 \mathrm{~W}_{\mathrm{p}}\right)$, optimally oriented for the geographical-climatic conditions present in Poland.

Figure 1 shows the connection diagram of the devices used in the fixed configuration of solar modules. 


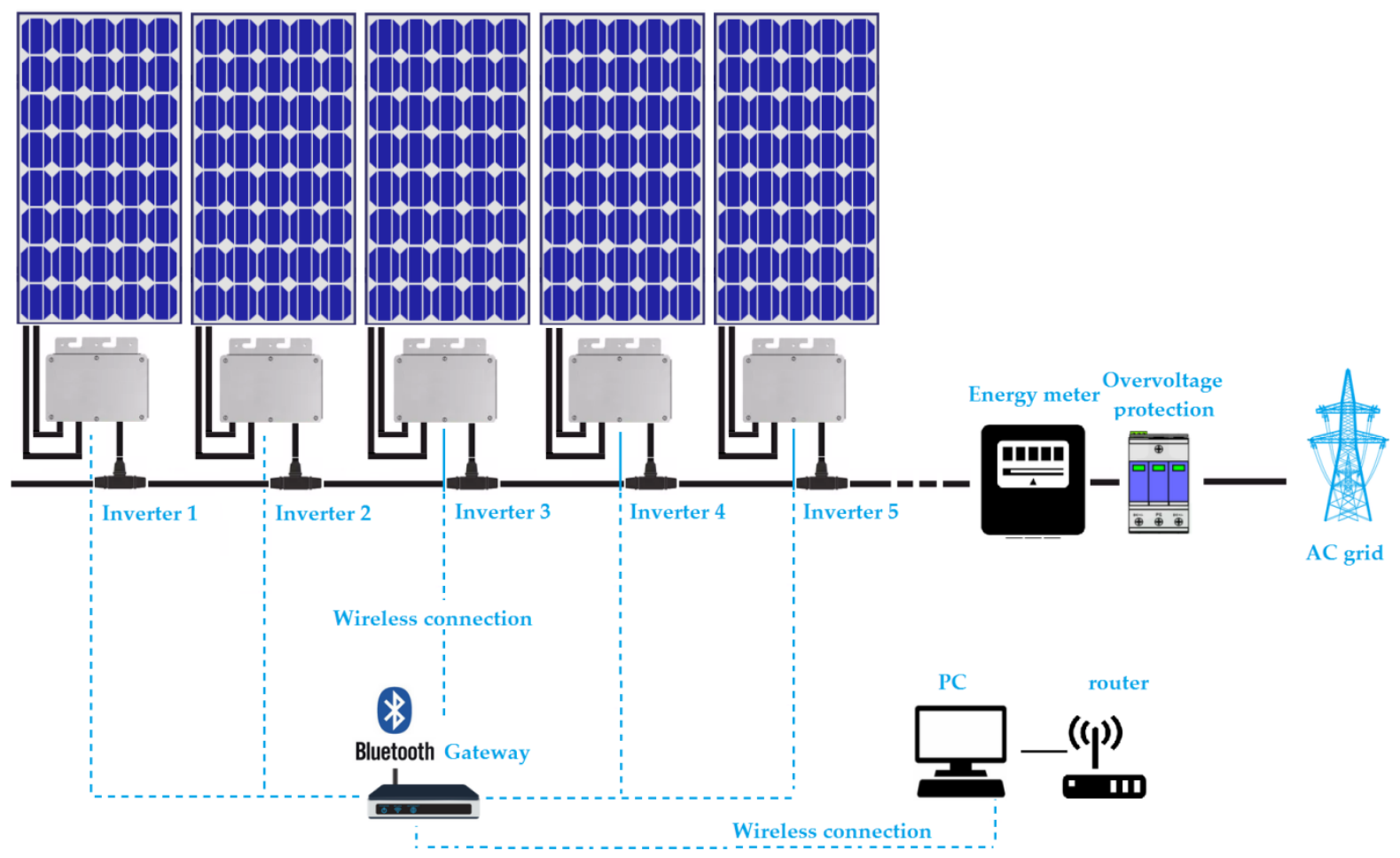

Figure 1. A diagram of the photovoltaic fixed system used in the comparative analysis with the tracking system.

Table 1 presents the parameters of the photovoltaic modules and microinverters used in fixed configuration.

Table 1. Electric and nonelectric parameters of the photovoltaic module and microinverters.

\begin{tabular}{|c|c|c|c|c|}
\hline & Photovoltaic Module & Value & DC/AC Microinverter & Value \\
\hline 1 & Maximum power & $200 \mathrm{~W}$ & Nominal input power & $240 \mathrm{~W}$ \\
\hline 2 & Voltage at power point & $29.64 \mathrm{~V}$ & Maximum DC voltage & $44 \mathrm{~V}$ \\
\hline 3 & Current at power point & $6.78 \mathrm{~A}$ & Minimum DC voltage & $20 \mathrm{~V}$ \\
\hline 4 & Open circuit voltage & $35.94 \mathrm{~V}$ & Range of MPPT & $23 \mathrm{~V} \ldots 35 \mathrm{~V}$ \\
\hline 5 & Short circuit & $7.6 \mathrm{~A}$ & Maximum input current & $12 \mathrm{~A}$ \\
\hline 6 & Efficiency & $12.61 \%$ & Temperature work & $-40^{\circ} \mathrm{C} \ldots 85^{\circ} \mathrm{C}$ \\
\hline 7 & Power tolerance & $+/-3 \%$ & Internal protection & IP66 \\
\hline
\end{tabular}

For the purposes of transforming electric energy generated by the photovoltaic modules, DC / AC microinverters were used and attached to a flat bar structure to track the maximum power point. The microinverters use Bluetooth technology to transmit data wirelessly to the system gateway unit.

The set of photovoltaic modules is characterized by its annual average angle of inclination of the plane to the ground $\beta=37^{\circ}$, determined on the basis of the algorithm presented in Figure 2. The calculations were conducted using input data in the form of the values of the direct and diffuse solar radiation intensity. The data were compiled on the basis of a typical meteorological year and statistical climatic data available for the city of Poznan [48]. By using the calculations in the iteration loop, for each new value of the angle of inclination $\beta$, incremented by one step, the value of the hourly insolation was calculated, and then this value was summed up in the daily and annual cycles. The values of calculated insolation for iteration marked $i$ were stored in created data table under item 
$t[i]$. The highest annual insolation (ins_max) occurs when the sought angle of inclination of the photoreceiver plane treated as the optimal angle $\beta_{\text {opt }}$ is adopted.

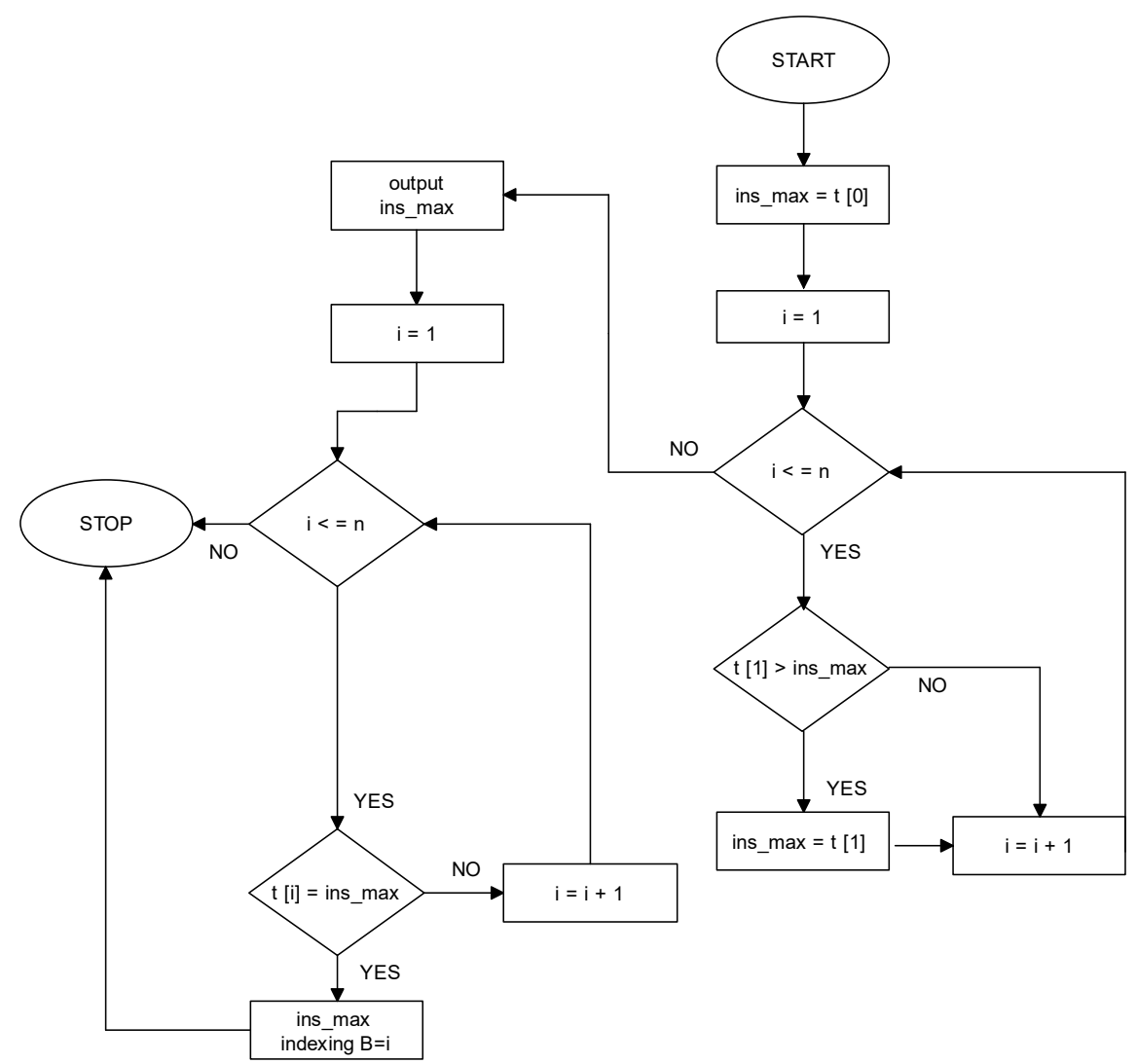

Figure 2. Algorithm for the determination of the angle of inclination of the plane of the photovoltaic modules installed in the fixed structure.

The parameter that determines the achievement of the optimal angle of inclination is the value of irradiation understood as the momentary insolation recorded on the measuring plane, which adopts the maximum value for the optimal value of the angle of inclination $\beta_{\text {opt }}$, in the entire range of its variability. In order to determine the value of irradiation, the modified isotropic mathematical model developed by Liu and Jordan, with the analytical form adapted to local climatic conditions (Central Poland, $52^{\circ} 24.4152^{\prime} \mathrm{N}, 16^{\circ} 55.7958^{\prime} \mathrm{E}$ ), was applied. The model was implemented in the Microsoft Visual C\# environment. The correction factor of diffuse radiation, which is a parameter that depends on the geographical location, is subject to modification.

In general, the Liu-Jordan isotropic model looks as follows [12]:

$$
\begin{aligned}
G_{\beta}= & G_{b} \cdot\left(\frac{\cos (\varphi-\beta) \cdot \cos \delta(t) \cdot \cos \omega(t)+\sin (\varphi-\beta) \cdot \sin \delta(t)}{\sin \varphi \cdot \sin \delta(t)+\cos \varphi \cdot \cos \delta(t) \cdot \cos \omega(t)}\right)+ \\
& +G_{d} \cdot\left(\frac{1+\cos \beta}{2}\right)+\left(G_{b}+G_{d}\right) \cdot \rho_{o} \cdot\left(\frac{1-\cos \beta}{2}\right)
\end{aligned}
$$

where $G_{b}$ and $G_{d}$ are the direct and diffuse components of solar radiation for the horizontal plane, $G_{\beta}$ is the total solar radiation on the plane inclined at angle $\beta, \varphi$ is the angle of latitude, $\delta(t)$ is the angle of sun declination, $\omega(t)$ is the hour angle, and $\rho_{o}$ is the reflectivity coefficient of the ground.

The relationship of the nonlinear solar radiation intensity estimator vs. the modified correction factor of the diffuse component, taking into account the angle of inclination of 
the plane of the solar receiver $\beta$, latitude $\varphi$, and sun declination $\delta$ may be presented in the form given in [12]:

$$
\begin{gathered}
\hat{G}_{\beta}=G_{b} \cdot\left(\frac{\cos (\varphi-\beta) \cdot \cos \delta(t) \cdot \cos \omega(t)+\sin (\varphi-\beta) \cdot \sin \delta(t)}{\sin \varphi \cdot \sin \delta(t)+\cos \varphi \cdot \cos \delta(t) \cdot \cos \omega(t)}\right)+ \\
+G_{d} \cdot\left(a_{0}+a_{1} \cdot \cos \left(a_{2} \cdot \beta+a_{3}\right)\right)+\left(G_{b}+G_{d}\right) \cdot \rho_{o} \cdot\left(\frac{1-\cos \beta}{2}\right)
\end{gathered}
$$

The value of the sought correction factor of the diffuse component of the solar radiation can be written as [12]

$$
\hat{R_{d}}=a_{0}+a_{1} \cdot \cos \left(a_{2} \cdot \beta+a_{3}\right)
$$

Mean squared error has been taken as the estimation criterion:

$$
\text { RMSE }=\sqrt{\frac{\sum_{n=1}^{12}\left(G_{\beta, n}-\hat{G}_{\beta, n}\right)^{2}}{n}}
$$

where $G_{\beta, n}$ is the measured value of solar radiation intensity and $n$ is the number of months in a measuring year.

In order to determine the generalized form of the correction factor of the diffuse component of solar radiation in the function of angle of inclination of the solar receive plane $\beta$, the RMSE criterion in the function of estimation parameters $a_{0}, a_{1}, a_{2}$, and $a_{3}$ was minimized.

$$
\frac{\partial \mathrm{RMSE}}{\partial a_{k}}=0 \text { for } \mathrm{k}=0,1,2,3
$$

where $a_{k}$ is the k-th estimation parameter forming the diffusion radiation correction factor and RMSE is the root-mean-square error.

In order to solve the aforementioned condition, the MATLAB environment, which enables searches for minimax solutions using the optimization toolbox, was used.

Figure 3 presents the course of the variability of correction factors determined for the respective angles of inclination of the receiver to the ground, including their approximation for all the analyzed angular positions.

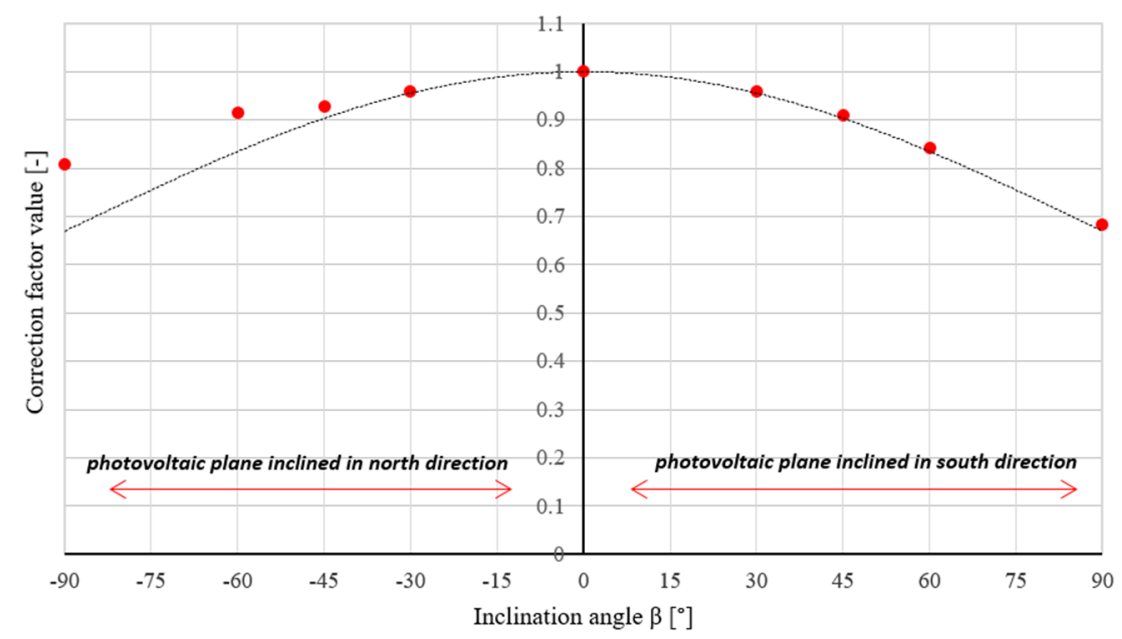

Figure 3. Variability of values of the correction factor in the function of the angle of inclination of the plane of the photovoltaic module and the determined approximating function for the entire angular range. 
The determined correction factor of the diffuse component of solar radiation as the approximating function which takes into account the angle of inclination of the photovoltaic receiver plane for the local climatic conditions of the city of Poznan takes the following form:

$$
R_{d}=0.046 p+\frac{2^{p}(p+q)(1+\cos \beta)+q}{2 p+q+2}+0.006 q
$$

Therefore, the irradiance on the plane inclined at any angle, on the basis of the modified Liu-Jordan method, taking into account the correction factor $R_{d}$, can be described as follows:

$$
\begin{aligned}
& G_{\beta}=G_{b} \frac{\sin \delta(t)[\sin \varphi \cos \beta-\cos \varphi \sin \beta \cos \gamma]}{\sin \delta(t) \sin \varphi+\cos \delta(t) \cos \varphi \cos \omega(t)}+ \\
& \frac{\cos \delta(t)[\cos \varphi \cos \beta \cos \omega(t)+\sin \varphi \sin \beta \cos \gamma \cos \omega(t)+\sin \beta \sin \gamma \sin \omega(t)}{\sin \delta(t) \sin \varphi+\cos \delta(t) \cos \varphi \cos \omega(t)}+ \\
& +G_{d}\left[0.046 p+\frac{2^{p}(p+q)(1+\cos \beta)+q}{2 p+q+2}+0.006 q\right]+\left(G_{b}+G_{d}\right) \rho_{o}\left(\frac{1-\cos \beta}{2}\right)
\end{aligned}
$$

where $G_{b}$ and $G_{d}$ are the direct and diffuse components of solar radiation for the horizontal plane, $G_{\beta}$ is the total solar radiation on the plane inclined at $\beta$ angle, $\varphi$ is the angle of latitude, $\gamma$ is the azimuth angle of the solar receiver, $\delta(t)$ is the angle of sun declination, $\omega(t)$ is the hour angle, $\rho_{o}$ is the reflectivity coefficient of the ground, and $p$ and $q$ are postoptimization adjustment parameters.

For the months of October-January, for which the percentage of the diffuse component in the total solar radiation, for a typical meteorological year of the city of Poznan, exceeds $75 \%$, the values of parameters $p$ and $q$ are 0 and 1, respectively, modifying the relationship (7) to the following form:

$$
\begin{aligned}
& G_{\beta}=G_{b} \frac{\sin \delta(t)[\sin \varphi \cos \beta-\cos \varphi \sin \beta \cos \gamma]}{\sin \delta(t) \sin \varphi+\cos \delta(t) \cos \varphi \cos \omega(t)}+ \\
& \frac{\cos \delta(t)[\cos \varphi \cos \beta \cos \omega(t)+\sin \varphi \sin \beta \cos \gamma \cos \omega(t)+\sin \beta \sin \gamma \sin \omega(t)}{\sin \delta(t) \sin \varphi+\cos \delta(t) \cos \varphi \cos \omega(t)}+ \\
& +G_{d}[0.67+0.33 \cos \beta]+\left(G_{b}+G_{d}\right) \rho_{o}\left(\frac{1-\cos \beta}{2}\right)
\end{aligned}
$$

For other months, for which the percentage of direct radiation increases in the global radiation, the values of parameters $p$ and $q$ are 1 and 0 , modifying factor $R_{d}$ to the following form:

$$
\begin{aligned}
& G_{\beta}=G_{b} \frac{\sin \delta(t)[\sin \varphi \cos \beta-\cos \varphi \sin \beta \cos \gamma]}{\sin \delta(t) \sin \varphi+\cos \delta(t) \cos \varphi \cos \omega(t)}+ \\
& \frac{\cos \delta(t)[\cos \varphi \cos \beta \cos \omega(t)+\sin \varphi \sin \beta \cos \gamma \cos \omega(t)+\sin \beta \sin \gamma \sin \omega(t)}{\sin \delta(t) \sin \varphi+\cos \delta(t) \cos \varphi \cos \omega(t)}+ \\
& +G_{d}[0.546+0.5 \cos \beta]+\left(G_{b}+G_{d}\right) \rho_{o}\left(\frac{1-\cos \beta}{2}\right)
\end{aligned}
$$

In order to determine the accuracy of the presented solar radiation model, calculations of the solar radiation density for selected days of each month of the year and for different inclination angles of the photovoltaic plane were made. The obtained results of calculations were compared with the results of measurements. Finally, the results were compared with five mathematical solar radiation models common in the literature, namely the Liu-Jordan, Hay, Badescu, Tian, Koronakis, and Steven and Unsworth models. The proposed model allowed the root-mean-square error (RMSE) and mean bias error (MBE) to be reduced in relation to the six different models. RMSE and MBE were calculated according to the following relations:

$$
\begin{aligned}
& \mathrm{RMSE}=\sqrt{\frac{\sum\left(C_{i}-M_{i}\right)^{2}}{n}} \\
& \mathrm{RMSE} \%=\frac{\mathrm{RMSE}}{\bar{M}} 100 \%
\end{aligned}
$$




$$
\begin{aligned}
& \mathrm{MBE}=\frac{\sum\left(C_{i}-M_{i}\right)}{n} \\
& \mathrm{MBE} \%=\frac{\mathrm{MBE}}{\bar{M}} 100 \%
\end{aligned}
$$

where $M$ is the average measured value of radiation power density on an inclined plane and $C$ is the calculated value of radiation power density on an inclined plane.

The value of the MBE may indicate whether there has been an overestimation or underestimation of the solar radiation intensity value, determined on the basis of the analyzed mathematical models, in relation to the measured value. The RMSE parameter makes it possible to state whether the selected mathematical model can be used, with high accuracy, to separate global solar radiation into direct and diffuse.

Table S1 in Supplementary Material shows the differences in RMSE\% and MBE\% of incident solar radiation of multiple models for a plane facing south at selected inclination angles of 30,45 , and $60^{\circ}$ located in Poznań, Poland.

Among many independent (explanatory) variables that have a potential effect on the analyzed dependent (response) variable, there are those that are critical for the value of the electricity produced in photovoltaic systems. Insolation, as the parameter that follows from the irradiance value, is directly correlated with the value of electricity from photovoltaic conversion, which determined the choice of this parameter as the criterion when determining the optimal angle of inclination of the planes of photovoltaic modules in the fixed module. Figure 4 presents the studied impact of the registered irradiance and the insolation determined on this basis on the value of electricity transmitted to the power grid using one of the designed photovoltaic systems.

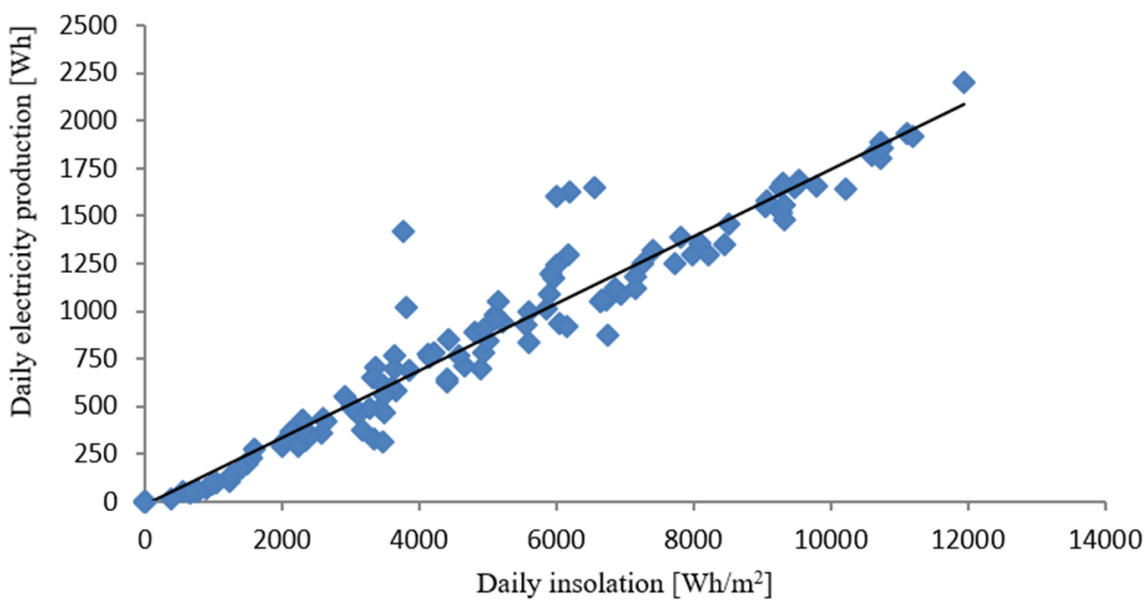

Figure 4. Impact of insolation on the value of electricity produced by the photovoltaic module in the fixed configuration.

Additionally, other variables recorded during the measurements, such as cloudiness $\left(e e \_z\right)$, length of day $\left(e e \_d d\right)$, pressure $\left(e e \_p\right)$, maximum air temperature $\left(e e \_t m p\right)$, precipitation (ee_o), sunshine duration (ee_u), and wind speed (ee_w), were subjected to evaluation. For this purpose, the value of the Pearson correlation coefficient for the impact of the respective independent variables on the dependent variable (in the form of daily electricity) was determined based on [49]:

$$
r_{x, y}=\frac{\frac{1}{n} \cdot \sum_{i=1}^{n}\left(x_{i}-\bar{x}\right) \cdot\left(y_{i}-\bar{y}\right)}{\sqrt{\frac{1}{n} \cdot \sum_{i=1}^{n}\left(x_{i}-\bar{x}\right)^{2}} \cdot \sqrt{\frac{1}{n} \cdot \sum_{i=1}^{n}\left(y_{i}-\bar{y}\right)^{2}}}=\frac{\operatorname{cov}(x, y)}{S_{x} \cdot S_{y}}
$$


where $S_{x}$ and $S_{y}$ are the deviations of the standard variable $x$ and $y$ and $n$ is the size of the population.

In characterizing the correlation between two variables, the direction and strength of the correlation should be described. The numerical expression of the correlation is the correlation coefficient within the range $<-1 ; 1>$. A correlation can be distinguished as positive ( $r_{x, y}$ ranges from 0 to 1$)$, informing that an increase in the value of one variable is accompanied by an increase in the mean values of the other feature, or negative ( $r_{x, y}$ varies from -1 to 0 ), informing that an increase in the value of one feature is accompanied by a decrease in the mean values of the other feature.

The strength of the correlation relationships depends on the value of the correlation coefficient: values below 0.2 , weak correlation (practically no relationship); $0.2-0.4$, low correlation (clear relationship); $0.4-0.6$, moderate correlation (significant correlation); $0.6-0.8$, high correlation (significant correlation); $0.8-0.9$, very high correlation (very high correlation); $0.9-1.0$, the relationship is practically complete.

The Pearson correlation coefficients determined for other explanatory variables are presented in Table 2. The response variable is defined in the analysis as the value of the daily production of electricity for the analyzed measuring period. The values of variables regarded as less significant in the forecasting process are marked in red.

Table 2. Values of Pearson correlation coefficients determined for the selected explanatory variables and the response variable.

\begin{tabular}{cccc}
\hline & Explanatory Variable & Symbol & Pearson Correlation Coefficient \\
\hline 1 & Daily insolation & $e e \_d n$ & 0.967 \\
\hline 2 & Cloudiness & $e e \_z$ & 0.679 \\
\hline 3 & Length of day & $e e \_d d$ & 0.202 \\
\hline 4 & Pressure & $e e \_p$ & 0.146 \\
\hline 5 & Maximum air temperature & $e e \_t m p$ & 0.442 \\
\hline 6 & Precipitation & $e e \_o$ & -0.250 \\
\hline 7 & Sunshine duration & $e e \_u$ & 0.904 \\
\hline 8 & Wind speed & $e e \_w$ & 0.212 \\
\hline
\end{tabular}

Table 3 presents the calculated values of the correlation coefficients between the explanatory variables, which occur with the highest Pearson correlation coefficient values in the form of daily insolation, cloudiness, maximum air temperature, and sunshine duration.

Table 3. The determined correlations between the explanatory variables.

\begin{tabular}{ccccc}
\hline \multirow{2}{*}{ Variable } & \multicolumn{4}{c}{ Pearson Correlation Coefficients } \\
\cline { 2 - 5 } & Daily Insolation & Cloudiness & Maximum Air Temperature & Sunshine Duration \\
\hline daily insolation & 1.000000 & 0.650988 & 0.510682 & 0.924923 \\
\hline cloudiness & 0.650988 & 1.000000 & 0.424817 & 0.652897 \\
\hline $\begin{array}{c}\text { maximum air } \\
\text { temperature }\end{array}$ & 0.510682 & 0.424817 & 1.000000 & 0.566304 \\
\hline sunshine duration & 0.924923 & 0.652897 & 0.566304 & 1.000000 \\
\hline
\end{tabular}

The highest rank in the statistical analysis is assigned to such variables as ee_dn and $e e \_u$. Figure 5 presents their impact on the response variable in the form of the daily electricity from photovoltaic conversion. Variables $e e \_d n$ and $e e \_u$ are strongly correlated with each other. In issues related to the periodical forecasting of electricity from photovoltaic conversion, superfluous variables are subject to reduction in order to avoid the artificial overestimation of the accuracy of the forecast model. 


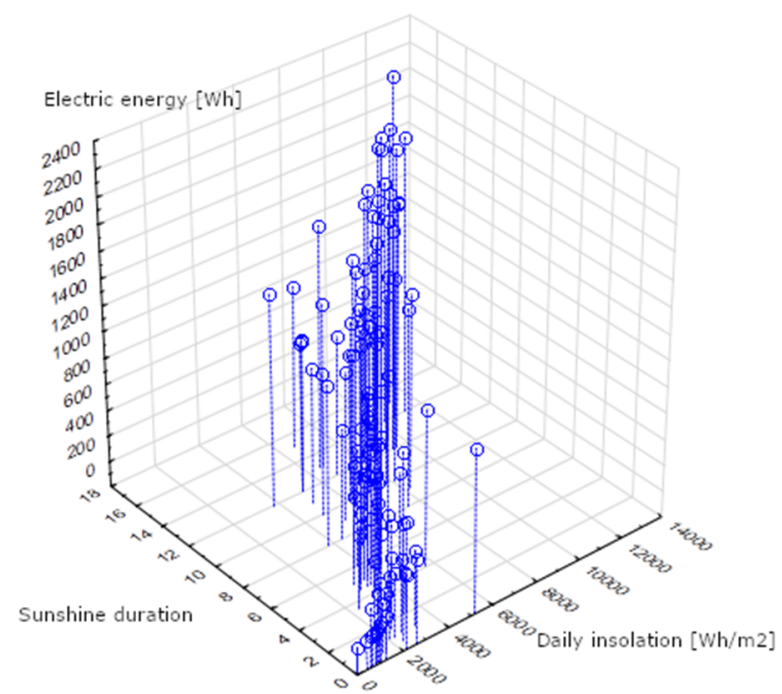

Figure 5. Impact of sunshine duration and insolation on the value of electricity from photovoltaic conversion.

For this reason, the insolation variable, which occurs with the highest rank in the conducted statistical analysis, was used as the criterion variable in the formulation of the objective function to the problem of optimization of the angle of inclination of the plane of photovoltaic modules in the fixed variant.

In addition to the power density of solar radiation reaching the receiver and the annual insolation, related to the geographical location, electric energy from photovoltaic conversion is also influenced by the value of the photovoltaic cells' operating temperature. This value indirectly depends on the ambient temperature, solar radiation power density, wind speed, and nominal operating cell temperature (NOCT) parameter. The electrical parameters of the photovoltaic module that vary as a function of temperature are voltage, current, and electric power. The intensity of these changes depends on the type of solar cell material. The polycrystalline photovoltaic modules used in the comparative tests are characterized by the temperature coefficients of $-0.35 \% /{ }^{\circ} \mathrm{C}$, and $0.05 \% /{ }^{\circ} \mathrm{C}$ for open-circuit voltage and short-circuit current, respectively.

On the basis of selected measurement days from the entire measurement period, a comparative summary was prepared in which the values of the recorded ambient temperature, the temperature of the back side of the photovoltaic module, and instantaneous electrical power, with the increasing value of the registered irradiance in the plane of the stationary module, are compiled. Results are presented in Table 4.

Based on the obtained results, the mutual correlations between the variables irradiance, photovoltaic module electric power, and module temperature were determined. They are presented in Table 5.

Based on the described range of variability of the correlation coefficient parameter, a moderate influence of the photovoltaic module temperature on the value of electric power was observed. It should be noted that the irradiance parameter has the greatest impact on the value of electric power; despite the increasing module temperature, the irradiance parameter contributes with greater value to the increase in the value of electric power. 
Table 4. Variability of recorded parameters for a wide range of measured irradiance.

\begin{tabular}{|c|c|c|c|c|c|c|c|c|c|}
\hline & $\begin{array}{c}E \\
\left(W / m^{2}\right)\end{array}$ & $\begin{array}{l}\mathrm{T}_{\mathrm{amb}} \\
\left({ }^{\circ} \mathrm{C}\right)\end{array}$ & $\begin{array}{c}\mathrm{T}_{\text {module }} \\
\left({ }^{\circ} \mathrm{C}\right)\end{array}$ & $\begin{array}{c}P_{\text {module }} \\
(W)\end{array}$ & & $\begin{array}{c}\text { Irradiance } \\
\left(\mathrm{W} / \mathrm{m}^{2}\right)\end{array}$ & $\begin{array}{l}\mathrm{T}_{\mathrm{amb}} \\
\left({ }^{\circ} \mathrm{C}\right)\end{array}$ & $\begin{array}{c}\mathrm{T}_{\text {module }} \\
\left({ }^{\circ} \mathrm{C}\right)\end{array}$ & $\begin{array}{c}P_{\text {module }} \\
(W)\end{array}$ \\
\hline 1 & 84.5 & 8.31 & 8.0 & 13.30 & 21 & 442.5 & 7.35 & 34.0 & 86.83 \\
\hline 2 & 109.4 & 10.26 & 11.9 & 17.24 & 22 & 456.3 & 6.05 & 12.7 & 84.21 \\
\hline 3 & 113.1 & 2.52 & 3.8 & 19.35 & 23 & 480.6 & 15.90 & 36.0 & 86.40 \\
\hline 4 & 120.5 & 10.35 & 11.8 & 19.20 & 24 & 481.8 & 13.70 & 40.2 & 95.17 \\
\hline 5 & 154.8 & 21.01 & 34.7 & 25.05 & 25 & 570.5 & 19.15 & 34.8 & 116.32 \\
\hline 6 & 172.1 & 2.06 & 7.4 & 24.59 & 26 & 587.1 & 3.36 & 17.3 & 108.85 \\
\hline 7 & 173.9 & 2.39 & 6.6 & 32.51 & 27 & 594.4 & 27.00 & 46.0 & 99.48 \\
\hline 8 & 195.3 & 7.79 & 9.3 & 42.29 & 28 & 659.9 & 18.77 & 38.3 & 121.89 \\
\hline 9 & 233.7 & 8.47 & 13.5 & 44.41 & 29 & 727.7 & 23.48 & 35.4 & 133.97 \\
\hline 10 & 269.7 & 4.36 & 14.6 & 43.84 & 30 & 774.9 & 25.77 & 36.1 & 125.15 \\
\hline 11 & 281.8 & 18.90 & 39.7 & 54.86 & 31 & 781.5 & 11.06 & 22.7 & 151.83 \\
\hline 12 & 307.8 & 7.85 & 12.0 & 56.18 & 32 & 852.7 & 23.09 & 43.6 & 152.24 \\
\hline 13 & 316.5 & 10.76 & 13.8 & 74.21 & 33 & 889.7 & 6.70 & 20.9 & 164.94 \\
\hline 14 & 346.4 & 25.85 & 38.3 & 61.16 & 34 & 915.5 & 26.77 & 50.9 & 152.69 \\
\hline 15 & 355.8 & 14.68 & 23.2 & 63.64 & 35 & 921.1 & 25.00 & 46.6 & 163.16 \\
\hline 16 & 377.5 & 25.34 & 34.2 & 79.40 & 36 & 958.0 & 11.43 & 29.8 & 182.23 \\
\hline 17 & 378.4 & 25.82 & 36.9 & 64.44 & 37 & 1083.4 & 25.88 & 42.2 & 192.98 \\
\hline 18 & 406.8 & 26.39 & 31.5 & 60.31 & 38 & 1128.0 & 13.65 & 35.2 & 202.02 \\
\hline 19 & 440.2 & 19.81 & 37.9 & 88.01 & 39 & 1129.1 & 28.03 & 44.2 & 203.91 \\
\hline 20 & 440.4 & 7.47 & 18.9 & 91.87 & 40 & 1137.7 & 24.75 & 46.3 & 215.45 \\
\hline
\end{tabular}

Table 5. The determined correlations between the explanatory variables.

\begin{tabular}{cccc}
\hline Variable & $\mathrm{E}\left(\mathrm{W} / \mathbf{m}^{2}\right)$ & $\mathbf{P}_{\text {module }}(\mathrm{W})$ & $\mathbf{T}_{\text {module }}\left({ }^{\circ} \mathbf{C}\right)$ \\
\hline $\mathrm{E}\left(\mathrm{W} / \mathrm{m}^{2}\right)$ & 1.000000 & 0.857797 & 0.453646 \\
\hline $\mathrm{P}_{\text {module }}(\mathrm{W})$ & 0.857797 & 1.000000 & 0.498896 \\
\hline $\mathrm{T}_{\text {module }}\left({ }^{\circ} \mathrm{C}\right)$ & 0.453646 & 0.498896 & 1.000000 \\
\hline
\end{tabular}

\subsection{Tracking Photovoltaic Installation}

The dual-axis tracking system allows for a change in the spatial orientation of photovoltaic modules using a control system that integrates astronomical positioning and sensor-based positioning. The mechanical system ensures a change in the angle of azimuth for the east-west direction in the range between -90 and $90^{\circ}$ in relation to the southern azimuth and a change in the angle of inclination ranging between 0 and $90^{\circ}$. The choice of the control strategy depends on the value of the irradiation of the solar radiation measured by an additional sensor in the form of a pyranometer, installed close to the tested system. Any registration of an irradiance value exceeding $200 \mathrm{~W} / \mathrm{m}^{2}$ causes the switching of the astronomical control to the sensor-based control.

Figure 6 presents the algorithm of the two-axis tracking system operation. 


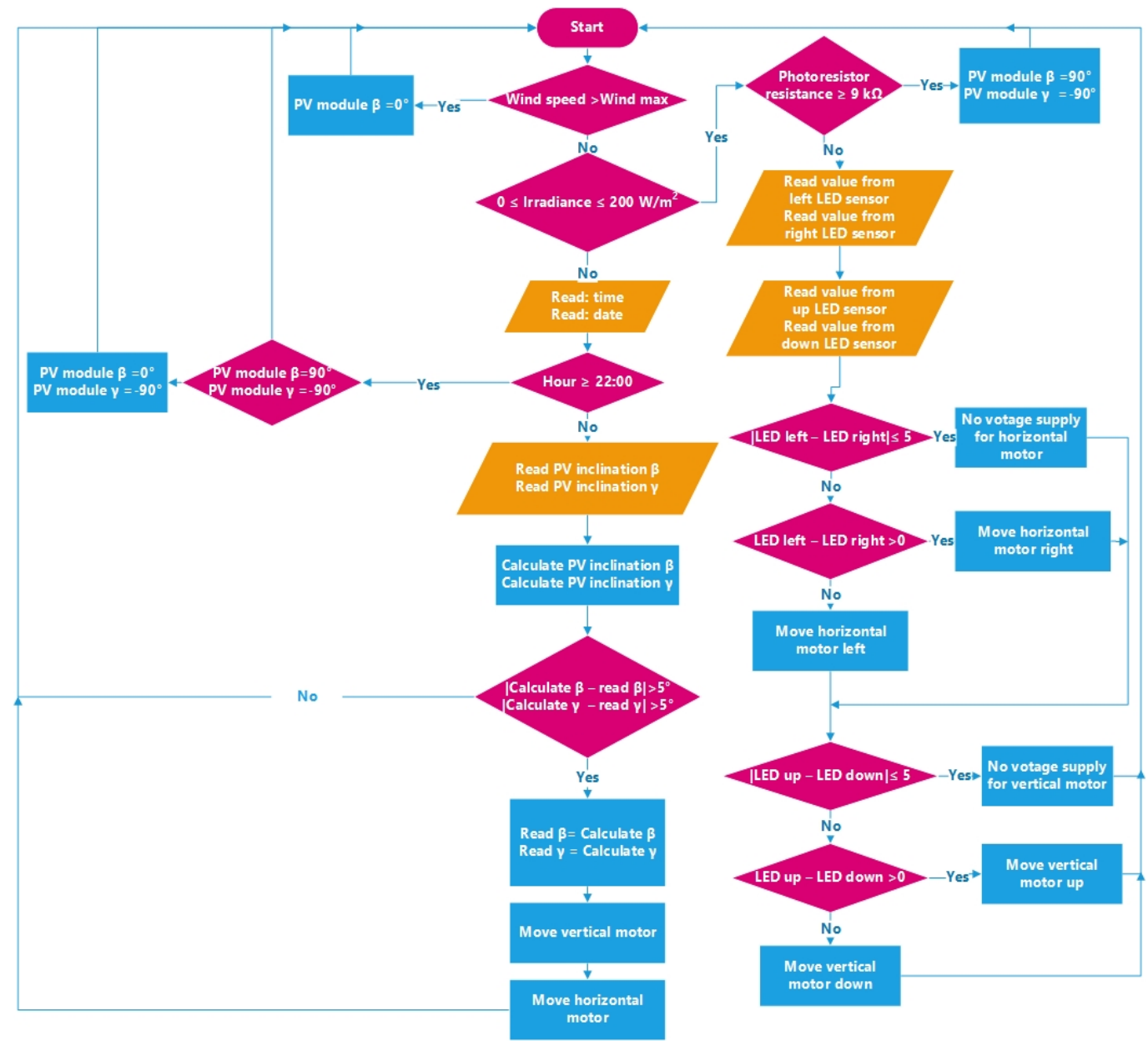

Figure 6. Implemented hybrid algorithm in two-axis tracking control unit.

A schematic diagram of the tracking system is presented in Figure 7.

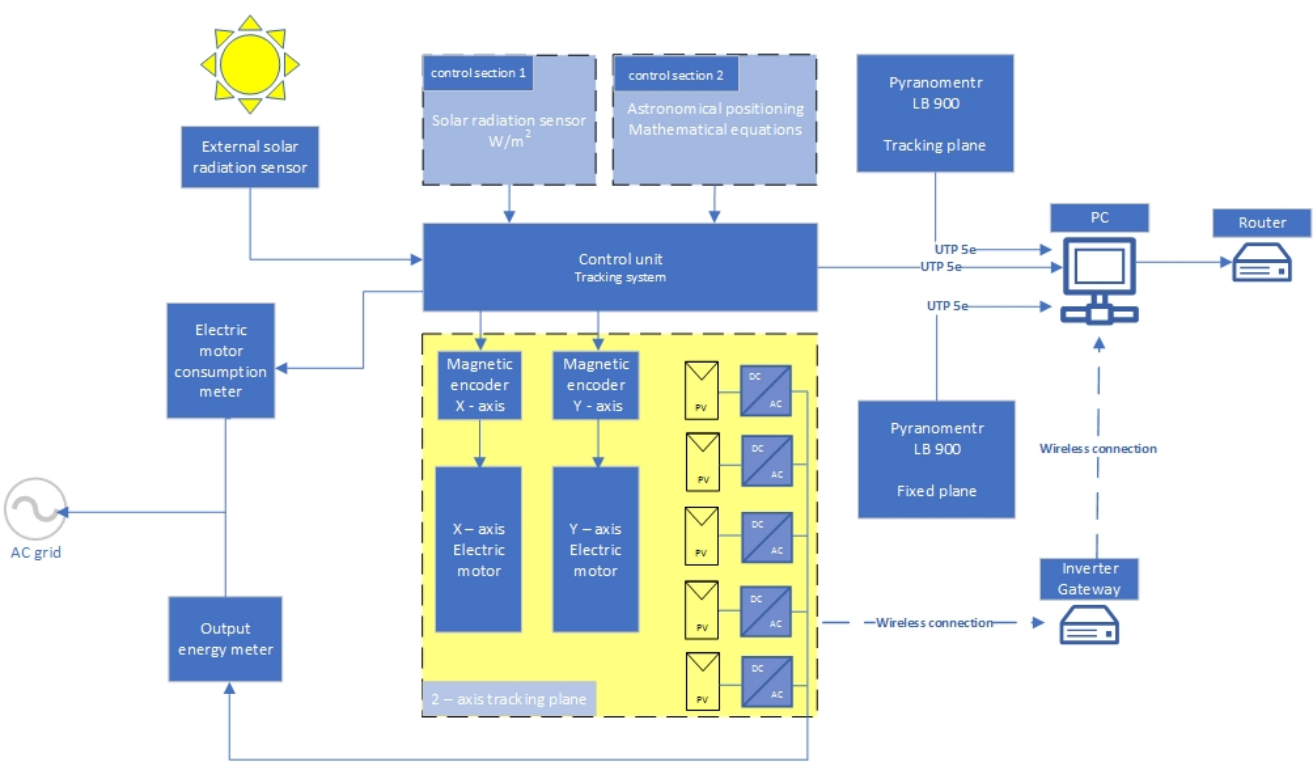

Figure 7. A schematic diagram of the MPPT control system.

The inverters used in the maximum power point tracking system use the perturbation and observation method $(P \mathcal{E O})$. In the $P \mathcal{E} O$ method, the operating voltage of the PV 
generator is disturbed by a small increase in $\mathrm{dU}_{\mathrm{PV}}$, and as a consequence, there is a change in power $\mathrm{dP}_{\mathrm{PV}}$. If the increase in power occurs, changes in operating voltage in the same direction should be continued. Otherwise, the direction of voltage increase should be changed. In the implemented method, the knowledge of the current-voltage characteristics of a PV generator is not required, which is the advantage of the method. The difficulty of the method is that with constant irradiation, the power of the generator oscillates around the maximum power point.

An image of the wiring diagram of the solar radiation detection block for the sensor-based control of each electrical actuator of the dual-axis tracking system is presented in Figure 8.

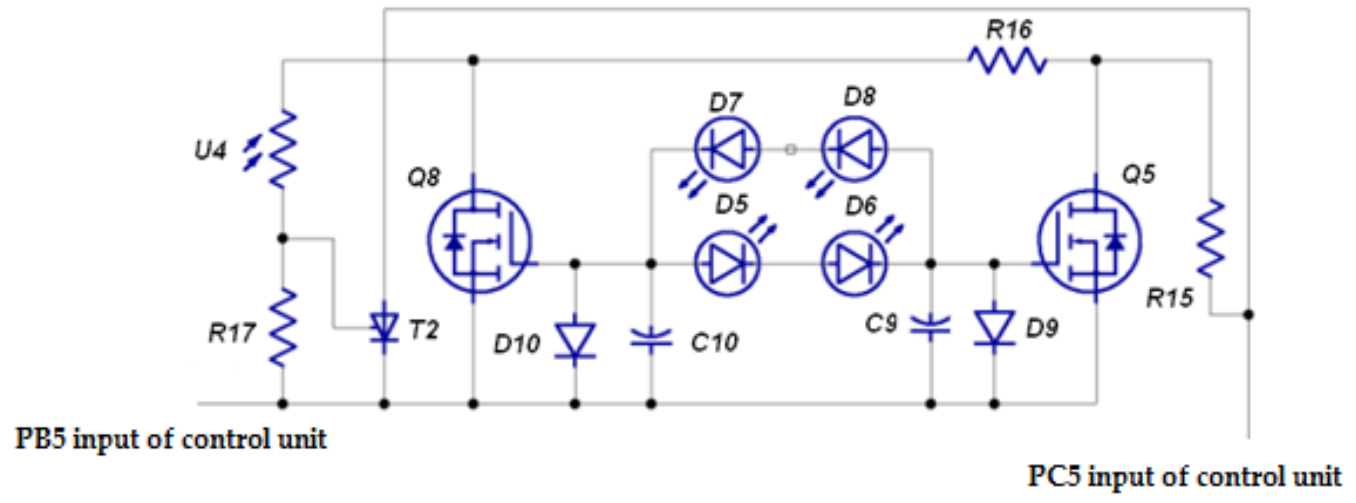

Figure 8. Wiring diagram of the solar radiation detection system for the sensor-based control of the change in the spatial orientation of photovoltaic modules on each axis.

The detection part presented in Figure 8, built of semiconductor elements, operates in a differential configuration and sends a signal to the control unit to supply the executive elements in the form of electric actuators. Based on different levels of voltage signals from diode sensors D5-D6 and D7-D8, which determine the state of balance of the illuminated photodetectors, the linear slide actuator is powered. This enables a change in the spatial orientation of the set of photocells. The supply voltage of the actuator is maintained until the state of balance, understood as the identity of voltages in both detection branches of semiconductor elements D5-D6-D7-D8, is obtained. Transistors Q8 and Q5 are the elements controlled in the differential solar radiation detection system. Uneven illumination of the pairs of photodetectors causes an exit from the state of balance and the appearance of voltage which controls the relevant transistor. The achievement of the end position, signaled by the activation of the integrated microswitches, allows for the system to be switched off for sunrise and sunset. The additional element in the form of the twilight detection photoresistor U4 enables the detection block to be switched off if there is no solar radiation. The system moves to its initial position, which approximates the eastern direction with the appropriate location of the structure in relation to the southern azimuth. The used linear slide actuators allow for a change in the position with a resolution of $1 \mathrm{~mm} / 380 \mathrm{imp}$.

The control algorithm implemented was provided using the Micro800 programmable controller. The determination of the position of the photovoltaic module is possible as a result of the application of incremental magnetic encoders. A sensor, in the form of an integrated circuit over which a magnet rotates in the axis of rotation of the actuator, measures the Hall voltage on electrode leads placed perpendicularly in relation to the magnetic field line, thus determining its strength, whose value depends on the actual tilt of the magnet. The task of the sensor is the detection of the angular translocation of the magnetic shield.

The use of the hybrid astronomical-sensor control is prompted by the frequent transmission of control signals and additional consumption of electricity in the situation of 
heavy cloud cover in the geographical location of the installation site of the photovoltaic modules. When the sky is covered partially or totally with clouds, the control system positioned the plane of photocells towards the brightest point on the sky, making the energy balance much worse.

Figure 9 presents the periodic consumption of electricity for the needs of the dual-axis positioning system for the first and second measuring year. Electricity was measured continuously for two years. On the basis of the daily values, the monthly values were determined.

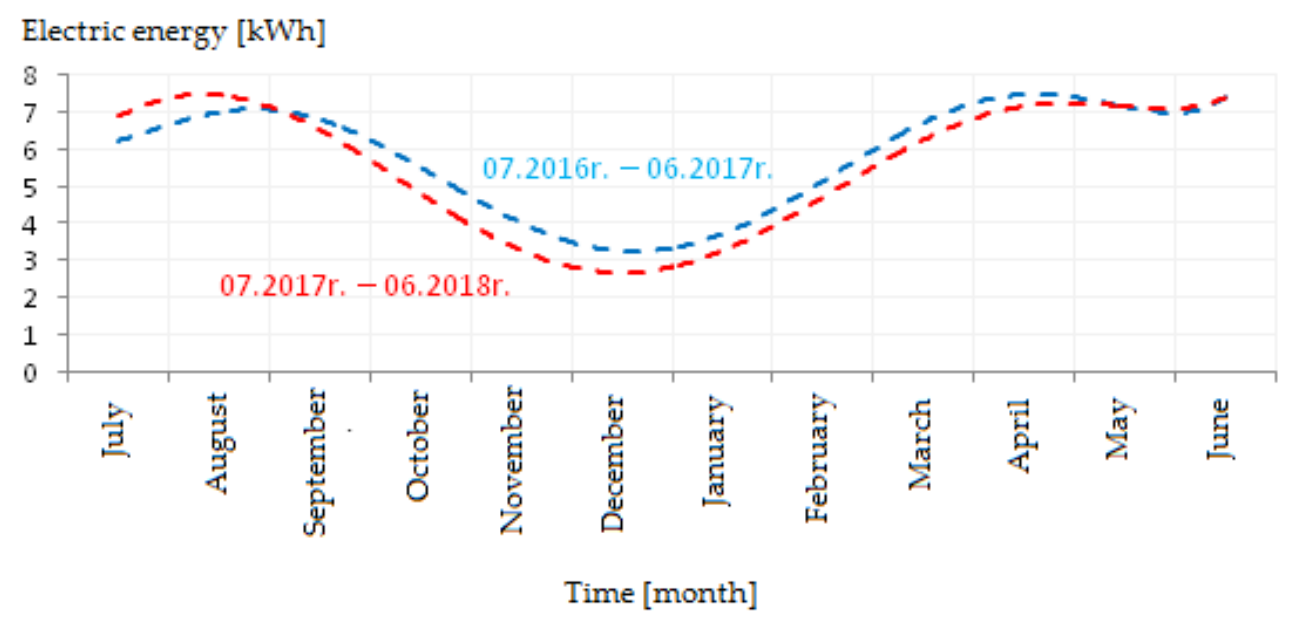

Figure 9. Changes in the consumption of electricity by electrical actuators vs. time- the first (07.201606.2017) and second (07.2017-06.2018) years of analysis.

An image of the single structure operating in the fixed system with the determined optimal angle of inclination and the dual-axis tracking system is presented in Figure 10.

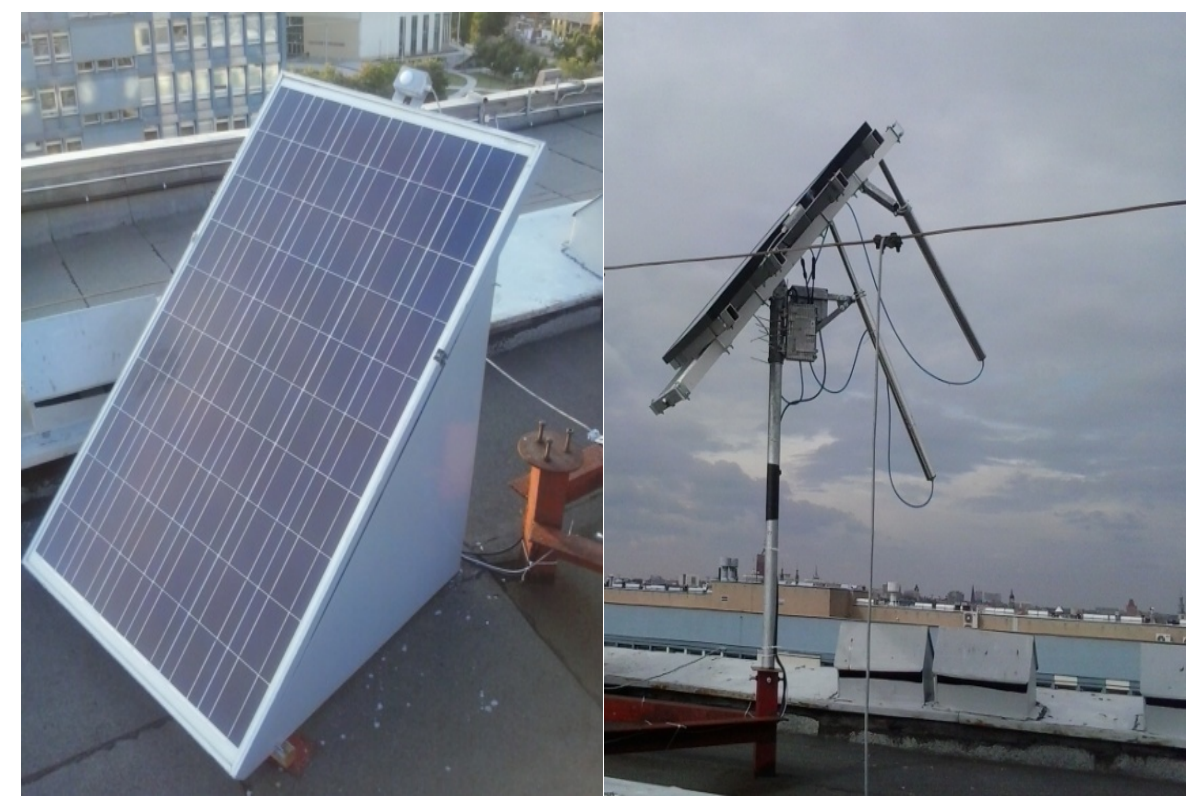

Figure 10. Image of the fixed and tracking photovoltaic system installed on the rooftop of the building of the Poznan University of Technology.

The dual-axis tracking system works together with a vane anemometer to measure the speed and direction of the wind. This allows the plane of the photovoltaic modules to be set in a horizontal position if the pre-set wind speed is exceeded, in order to protect the system from mechanical damage. 
Within the plane of the silicon modules, solar radiation power density sensors were also installed. These sensors consist of a microprocessor measuring system. The instrument is provided with a digital current interface with transients compliant with the RS232 standard. By using a converter, the meters were connected to the master data collection system. This enables registration of the total solar radiation within the plane of each photovoltaic module at 10-s increments, both in the fixed and tracking configuration. Each photovoltaic module works with a transformerless microinverter that operates the global tracking of the maximum power point (MPPT), which is connected directly to the power grid. The converters used enable the wireless transmission of the data being measured to the data archiving system in the form of a PC using Bluetooth technology.

\section{Results}

The percentage gain and value of electricity produced by the dual-axis tracking system and fixed system during the first and second years of analysis are presented in Tables 6 and 7. Red was used to mark the cases when the fixed system was characterized by better energy efficiency when compared to the solar tracking system.

Table 6. Percentage gain and value of electricity produced by the dual-axis tracking system and fixed system in the period between 07.2016 and 06.2017.

\begin{tabular}{|c|c|c|c|c|c|}
\hline $\begin{array}{c}\text { Month of the } \\
\text { Year }\end{array}$ & $\begin{array}{c}\text { Tracking System } \\
\text { Gross Electricity } \\
\text { (kWh) }\end{array}$ & $\begin{array}{c}\text { Tracking System } \\
\text { Net Electricity } \\
\text { (kWh) }\end{array}$ & $\begin{array}{l}\text { Fixed System } \\
\text { (kWh) }\end{array}$ & $\begin{array}{l}\text { Gross Increase in } \\
\text { Electricity }(\%)\end{array}$ & $\begin{array}{l}\text { Net Increase in } \\
\text { Electricity [\%] }\end{array}$ \\
\hline 07.2016 & 164.8 & 158.5 & 116.15 & 41.89 & 36.46 \\
\hline 08.2016 & 167.2 & 160.3 & 124.75 & 34.03 & 28.5 \\
\hline 09.2016 & 90 & 83.1 & 87 & 3.45 & 4.7 \\
\hline 10.2016 & 76.8 & 70.9 & 61.4 & 25.08 & 15.5 \\
\hline 11.2016 & 22.3 & 18.4 & 18.85 & 18.30 & 2.4 \\
\hline 12.2016 & 17.5 & 14.6 & 16.45 & 6.38 & 12.7 \\
\hline 01.2017 & 32.8 & 29.1 & 28.4 & 15.49 & 2.5 \\
\hline 02.2017 & 84.4 & 78.4 & 65.15 & 29.55 & 20.3 \\
\hline 03.2017 & 102.3 & 96.1 & 79.1 & 29.33 & 21.5 \\
\hline 04.2017 & 129.2 & 121.8 & 96.1 & 34.39 & 26.7 \\
\hline 05.2017 & 175.25 & 167.8 & 112.1 & 56.33 & 49.7 \\
\hline 06.2017 & 188.45 & 181.1 & 117.35 & 60.59 & 54.3 \\
\hline \multicolumn{2}{|c|}{ Annual gain $(\%)$} & gross & 35.56 & Net & 27.88 \\
\hline
\end{tabular}

Table 7. Percentage gain and value of electricity produced by the dual-axis tracking system and fixed system in the period between 07.2017 and 06.2018 .

\begin{tabular}{|c|c|c|c|c|c|}
\hline Month of the Year & $\begin{array}{c}\text { Tracking System } \\
\text { Gross Electricity } \\
\text { (kWh) }\end{array}$ & $\begin{array}{c}\text { Tracking System } \\
\text { Net Electricity } \\
\text { (kWh) }\end{array}$ & $\begin{array}{l}\text { Fixed System } \\
\text { (kWh) }\end{array}$ & $\begin{array}{l}\text { Gross Increase in } \\
\text { Electricity }(\%)\end{array}$ & $\begin{array}{l}\text { Net Increase in } \\
\text { Electricity (\%) }\end{array}$ \\
\hline 07.2017 & 190.75 & 183.9 & 124.95 & 52.66 & 47.2 \\
\hline 08.2017 & 168.7 & 161.1 & 114.9 & 46.82 & 40.2 \\
\hline 09.2017 & 145.75 & 139.5 & 107.15 & 36.02 & 30.2 \\
\hline 10.2017 & 85.7 & 80.6 & 64.1 & 33.70 & 25.7 \\
\hline 11.2017 & 26.15 & 22.9 & 20.55 & 27.25 & 11.4 \\
\hline 12.2017 & 15.7 & 12.9 & 12.05 & 30.29 & 7.1 \\
\hline 01.2018 & 23 & 19.9 & 19.05 & 20.73 & 4.5 \\
\hline 02.2018 & 64.7 & 60.1 & 47.75 & 35.50 & 25.9 \\
\hline 03.2018 & 121.45 & 114.7 & 86.65 & 40.16 & 32.4 \\
\hline 04.2018 & 139.25 & 132.6 & 102.9 & 35.33 & 28.9 \\
\hline 05.2018 & 177.6 & 170.2 & 113.4 & 56.61 & 50.1 \\
\hline 06.2018 & 185.25 & 177.9 & 115.6 & 60.25 & 53.9 \\
\hline \multicolumn{2}{|c|}{ Annual gain $(\%)$} & gross & 44.66 & Net & 37.38 \\
\hline
\end{tabular}


Figures 11 and 12 present the variability of the monthly and accumulated electricity produced by photovoltaic modules in different configurations and the variability of insolation being in correlation with electricity, recorded on both measuring planes.

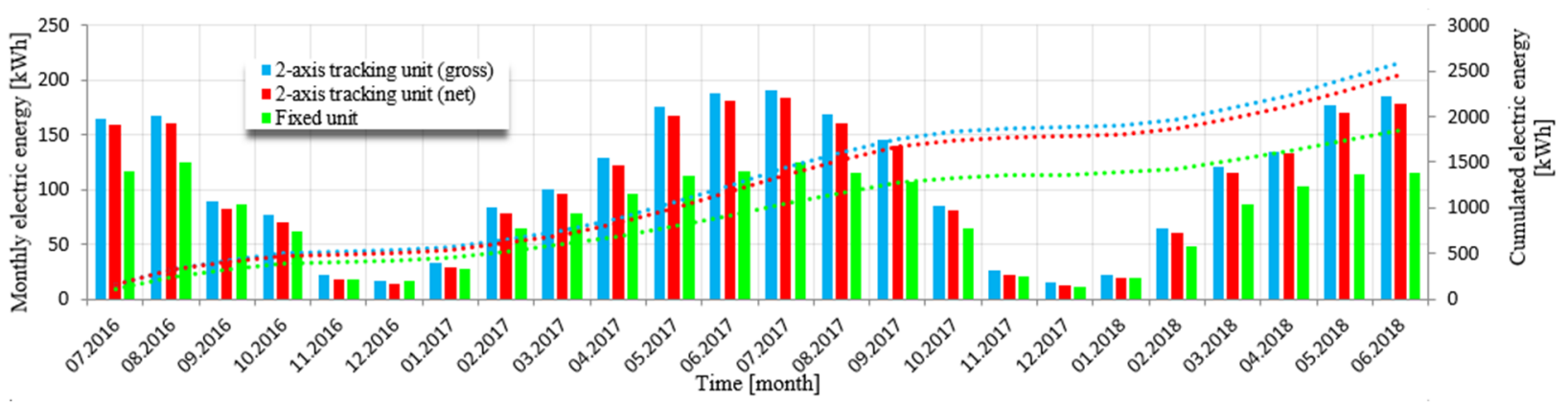

Figure 11. Variability of electricity produced by photovoltaic modules in the fixed and dual-axis tracking configurations for a two-year measuring period and accumulated value, taking into account the consumption for the purpose of supplying actuators.

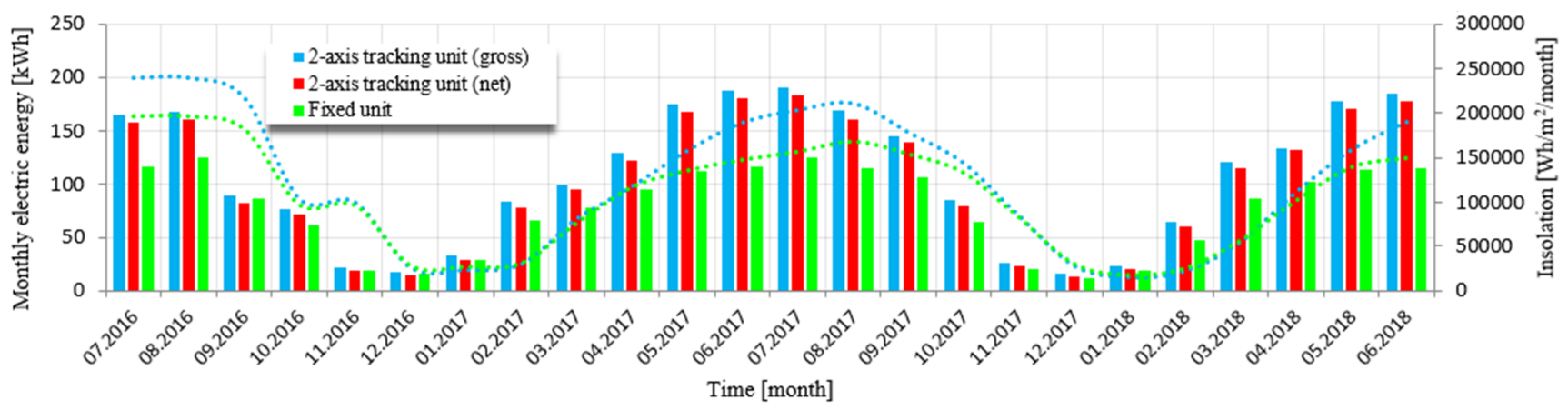

Figure 12. Variability of electricity produced by photovoltaic modules in the fixed and dual-axis tracking configurations for a two-year measuring period and insolation recorded on both planes.

Gross electricity is electricity produced by photovoltaic modules in a follow-up system without taking into account its consumption for the purposes of powering actuators.

Net electricity is electricity produced by photovoltaic modules in a follow-up system, taking into account its consumption for the purposes of powering actuators.

The results of the electricity production and the determined insolation for selected months of the full measuring period are presented in Figures 13-17. The monthly production of electricity indicates the periods in which the use of positioning is energetically justified, as it leads to significant, even as much as $60 \%$ (for selected days), energy gains in relation to the fixed system (Figure 13). As a consequence of significant cloud cover and the significant share of diffuse radiation in the total solar radiation, those months with limited efficiency are also presented (Figure 14). 


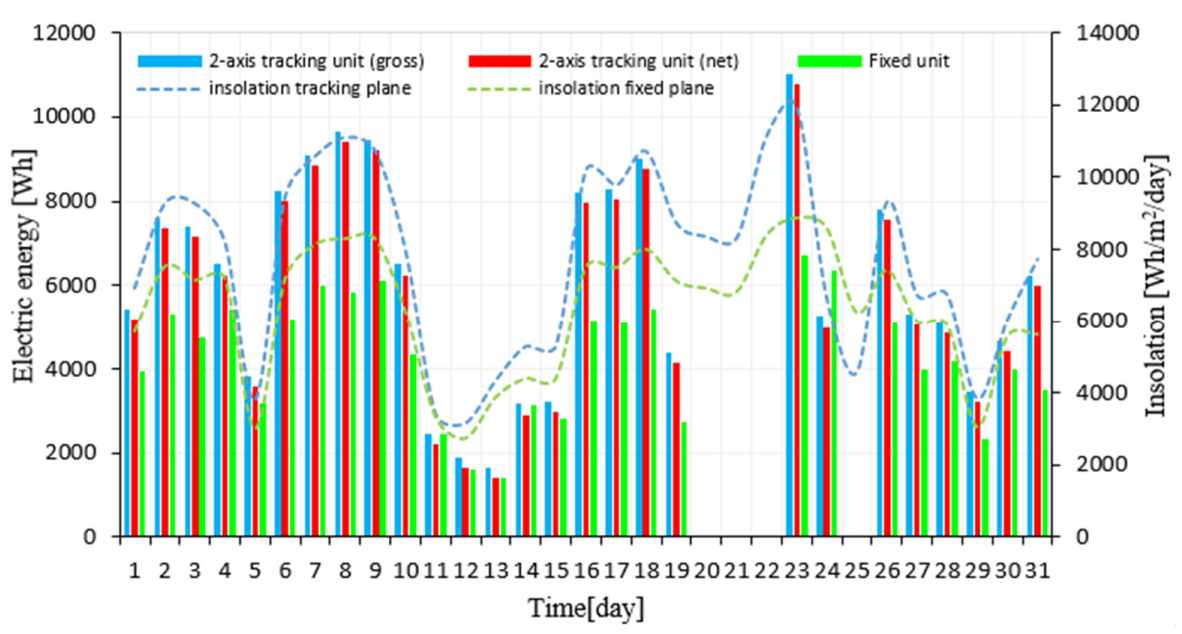

Figure 13. Variability of the electricity production and the determined insolation for photovoltaic modules in the fixed and dual-axis tracking configurations in July 2016.

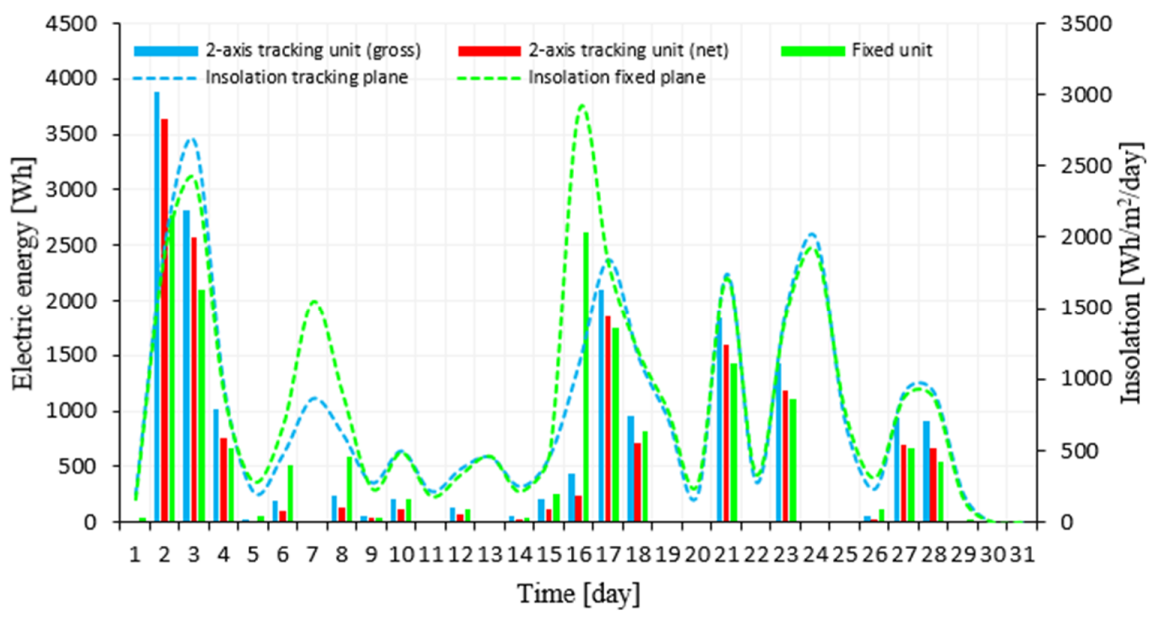

Figure 14. Variability of the electricity production and the determined insolation for photovoltaic modules in the fixed and dual-axis tracking configurations in December 2016.

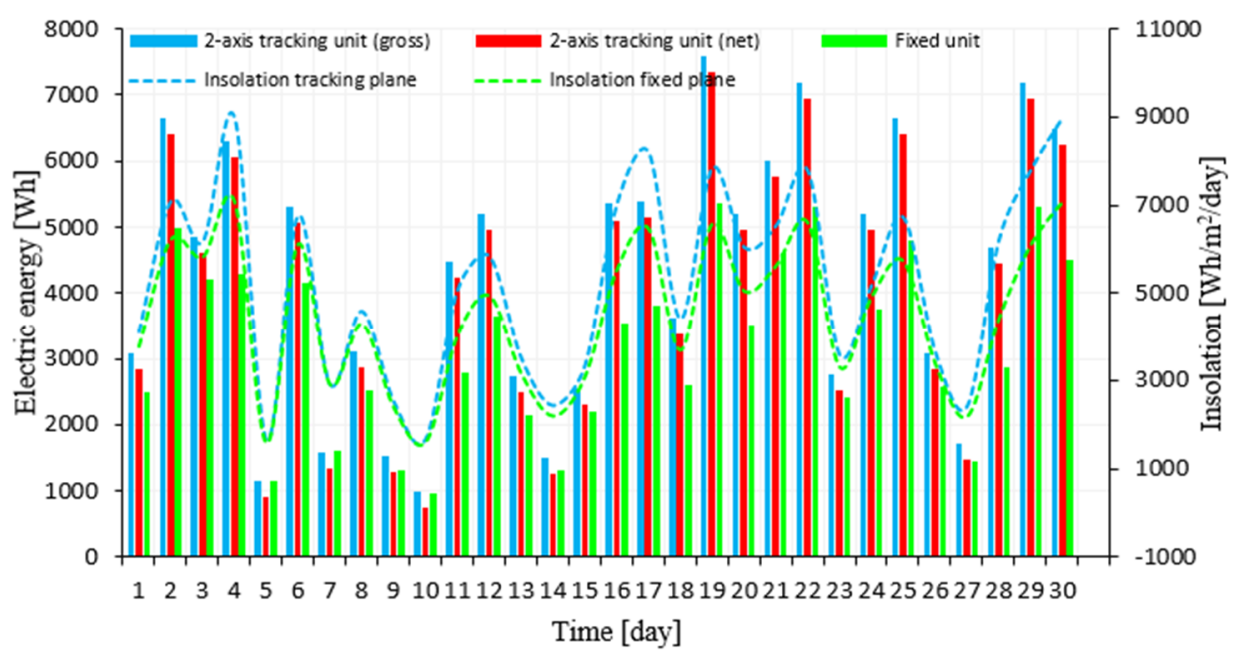

Figure 15. Variability of the electricity production and the determined insolation for photovoltaic modules in the fixed and dual-axis tracking configurations in April 2017. 


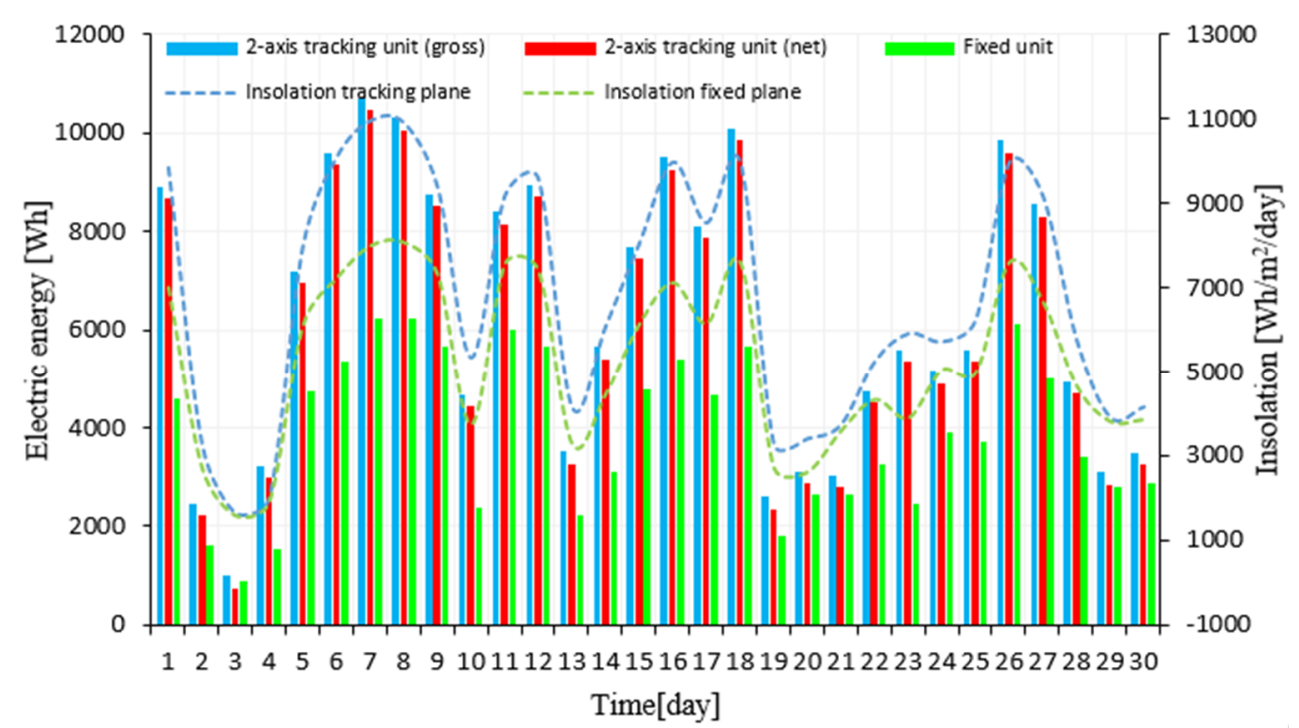

Figure 16. Variability of the electricity production and the determined insolation for photovoltaic modules in the fixed and dual-axis tracking configurations in June 2017.

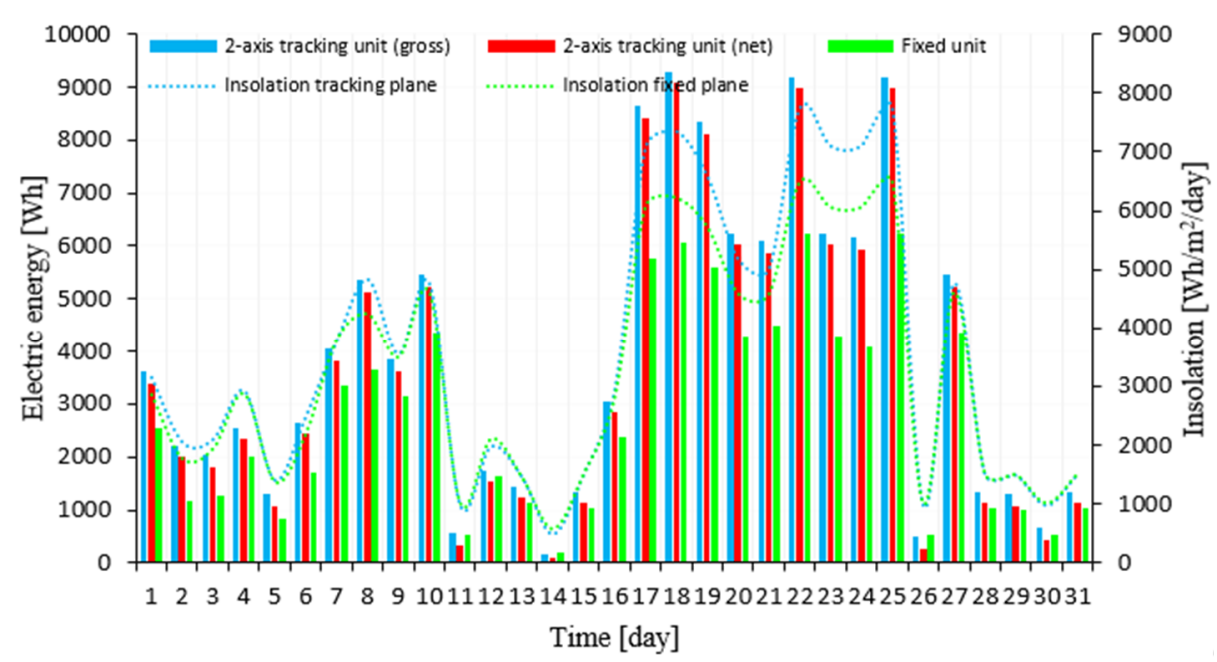

Figure 17. Variability of the electricity production and the determined insolation for photovoltaic modules in the fixed and dual-axis tracking configurations in March 2018.

\section{Discussion and Conclusions}

The aforementioned discussion and the 24-month long-term comparative analysis of the tested PV configurations confirm that the application of dual-axis solar tracking systems is beneficial for the analyzed geographical location and increases the performance of the tested polycrystalline photovoltaic modules, whereby the energy gains are particularly high during summer months.

The proposed solar radiation model used to determine the optimal value of the angle of inclination for a stationary photovoltaic installation takes into account the different levels of direct and diffuse radiation during the year. The presented correction factor takes two forms depending on the total amount of the contribution of diffuse radiation, reducing annual average $\mathrm{MBE} \%$ for inclination angles 30,45 , and $60^{\circ}$ to $1.1 \%,-0.6 \%$, and $-3.1 \%$ from $-1.97 \%,-5.58 \%$, and $-7.05 \%$ for the well-known Liu-Jordan model. As a result, monthly RMSE\% and MBE\% were reduced, for example for selected settings of $30-45^{\circ}$ to $<0.79 \%-8.5 \%>$ and $<-2.8 \%-2.4 \%>$, respectively, as presented in Table 1 (SM). The proposed mathematical model can be used to determine the value of irradiance on the plane of the photoreceiver inclined at an angle with respect to the ground, based on the value of irradiance on the horizontal plane. The form of dependence has been adapted 
to the Polish climatic conditions on the basis of solar radiation distribution, taking into account the direct and diffuse components of global radiation.

The use of the system of spatial positioning of photovoltaic modules using astronomicalsensor control enabled an increase in the production of electricity from photovoltaic conversion by $40 \%$ (without taking into account its consumption by the positioning system for its own needs) and by $32.6 \%$ (taking into account the consumption of electricity) in the period between July 2016 and June 2018.

The gross energy gain as a result of the implementation of the hybrid astronomicalsensor-controlled algorithm in the dual-axis system amounted to $56.33 \%, 60.59 \%, 52.66 \%$, and $46.82 \%$ and the net energy gain was $49.7 \%, 54.3 \%, 47.2 \%$, and $40.2 \%$ for the selected months of May, June, July, and August 2017 respectively.

There is a periodical repeatability of recorded values of the monthly production of electricity, especially for the periods with low cloud cover such as August 2016 and August 2017, in which it amounted to 167.2 and $168.7 \mathrm{kWh}$, respectively, for the dual-axis tracking modules and 124.75 and $114.9 \mathrm{kWh}$, respectively, for the fixed modules. The value of the monthly insolation on the tracking and fixed planes for August 2016 was 226,910 and $192,576 \mathrm{Wh} / \mathrm{m}^{2}$, respectively and 188,668 and $164,193 \mathrm{Wh} / \mathrm{m}^{2}$ in the following year.

The impact of the operating temperature of the silicon cells on electrical parameters such as voltage and momentary electrical power is marked. These parameters correlate with the value of electricity obtained during the summer months. This impact can be observed, for instance, on the 3rd and 23rd days of July 2016, where the summarized value of the daily production of electricity for a similar value of daily insolation is observed in reference to the tracking modules and the fixed modules, that is, 7600 and $4750 \mathrm{Wh}$, respectively, in July 2016 and 11,010 and 6730 Wh in July 2017. A similar relationship is observed for other days of those months with high average daily values of air temperature. This situation is the result of a reduction in the value of the open-circuit voltage and the voltage at the maximum power point, in the case of the optimal power load, while this effect does depend on the value of the temperature coefficients of these electrical parameters.

Analysis of the obtained measurement results has demonstrated that the positioning of photovoltaic modules using the system which changes its position on both axes allows for an improvement in the heat transfer conditions, ensuring better ventilation as a consequence of natural air motion at the bottom part of the photovoltaic module base, thus preventing the negative effect of temperature on the electrical parameters of the semiconductor junction.

For the winter months, there is a lack of repeatability in the distribution of the monthly insolation and the obtained electricity in relation to similar results obtained during the subsequent years (Figure 14). The stochastic distribution of the radiation power density makes it difficult to forecast the generation of electricity from photovoltaic installations during those periods of the year in both variants, the fixed and the tracking installation of PV modules.

Despite the limited energy efficiency of the modules installed in the tracking system in relation to the fixed configuration during the winter period (Figure 14), it was demonstrated that the value of electricity produced during that period does not exceed $20 \%$ of the total electricity produced in the period between May and September, which consequently has a positive effect on the annual energy balance of the dual-axis positioning system used.

The maximum monthly consumption of electricity (Figure 9) to ensure the continuity of the power supply for the applied electrical actuators slightly exceeds $7.5 \mathrm{kWh}$. Limitation of this value must be sought in the selection of the actuator switching frequency and in the search for new, energy-saving electrical drives and passive systems.

Analysis of the two-year production of electricity indicates the months for which the use of PV module spatial positioning systems is particularly justified, ensuring electrical energy gains when compared to the fixed configuration (Figure 16), and the periods of limited efficiency related mainly to long-lasting cloudiness. 
By analyzing the distribution of solar radiation power density by means of pyranometers, insolation, and diagrams of electric energy generation, it was found that the efficiency of the tracking system was more advantageous than that of the fixed one, above all at early and evening hours and when the sky was clear, and that it was illegitimate to use the positioning system on days with heavy clouds. The two-axis positioning system is found more advantageous in the evening hours, a feature which can be used for living purposes provided the power is high enough, so that users early in the morning and in the evening can use the energy stored, for example, to heat utility water.

The efficiency of the sun-tracking systems depends on the type of positioning (astronomical, sensor, hybrid control), the radiation source detecting method, the frequency of moving the photovoltaic modules, and the angular operating range. For geographical locations with a significant contribution of diffuse radiation in total solar radiation, the use of astronomical-sensor positioning should be considered. The use of a two-axis tracking system with voltage signal control from an external sensor in the initial stage of the research turned out to be particularly unfavorable in the situation of moderate and strong cloud cover. It led to a reduction in the instantaneous electric power with additional use of electric energy by the actuators and frequent unnecessary positioning towards the brightest point. For this reason, the authors modified the system using closed-loop control (astronomical positioning) and open-circuit control with the use of an external solar radiation sensor.

The proper selection and adjustment of the control algorithm to the current climatic conditions that describe the place of photovoltaic module operation seems to be necessary taking into account the nature of the total solar radiation distribution and contribution of the direct, diffuse, and even reflected radiation.

The obtained results of long-term analysis of electricity production can be used in complex economic analysis of two-axis sun-tracking system applications with hybrid astronomical-sensor control. Taking into account the increase in electric energy production in a two-axis tracking installation, including extra cost resulting from the applied structures and current support system provided by the country, it is possible to assess the investment payback period and operational costs.

Supplementary Materials: The following are available online at https: / www.mdpi.com/article/ 10.3390/en14102938/s1, Figure S1: Variability of the electricity production and the determined insolation for photovoltaic modules in the fixed and dual-axis tracking configurations in August 2016. Figure S2: Variability of the electricity production and the determined insolation for photovoltaic modules in the fixed and dual-axis tracking configurations in August 2017. Table S1: Values of $\mathrm{RMSE} \%$ and $\mathrm{MBE} \%$ for tested models.

Author Contributions: The design and construction of photovoltaic units were conducted by A.B. The solar radiation model analyses presented in this manuscript and the evaluation were carried out by G.F.-J., A.B. and G.F.-J. supervised the research and prepared the manuscript. All authors have read and agreed to the published version of the manuscript.

Funding: This research received no external funding.

Institutional Review Board Statement: Not applicable.

Informed Consent Statement: Not applicable.

Data Availability Statement: Not applicable.

Conflicts of Interest: The authors declare no conflict of interest. 


\section{Nomenclature}

\begin{tabular}{|c|c|c|}
\hline Acronym & Meaning & Units \\
\hline$\beta$ & angle of inclination of the photovoltaic module plane to the ground & \\
\hline ins_max & the highest annual insolation & $\mathrm{Wh} \cdot \mathrm{m}^{-2}$ \\
\hline$\beta_{\text {opt }}$ & optimal inclination angle of the photovoltaic module & \\
\hline$G_{b}, G_{d}$ & direct and diffuse component of solar radiation for the horizontal plane & $W \cdot m^{-2}$ \\
\hline$G_{\beta}$ & total solar radiation on the plane inclined at angle $\beta$ & $\mathrm{W} \cdot \mathrm{m}^{-2}$ \\
\hline$\varphi$ & angle of latitude & $\circ$ \\
\hline$\delta(t)$ & angle of sun declination & $\circ$ \\
\hline$\omega(t)$ & hour angle & $\circ$ \\
\hline$\rho_{0}$ & reflectivity coefficient of the ground & - \\
\hline RMSE & root-mean-square error & - \\
\hline MBE & mean bias error & - \\
\hline$R_{d}$ & correction factor of the diffuse component of solar radiation & - \\
\hline$\gamma$ & azimuth angle of the solar receiver & o \\
\hline$p, q$ & postoptimization adjustment parameters & - \\
\hline $\mathrm{M}$ & average measured value of radiation power density on an inclined plane & $W \cdot m^{-2}$ \\
\hline $\mathrm{C}$ & calculated value of radiation power density on an inclined plane & $W \cdot m^{-2}$ \\
\hline$e e \_z$ & cloudiness variable & - \\
\hline ee_dd & length of day & $\mathrm{h}$ \\
\hline$e e \_p$ & external pressure & $\mathrm{Pa}$ \\
\hline ee_tmp & maximum air temperature & ${ }^{\circ} \mathrm{C}$ \\
\hline$e e \_o$ & precipitation & $\mathrm{mm}$ \\
\hline$e e \_u$ & sunshine duration & $\mathrm{h}$ \\
\hline$e e \_w$ & wind speed & $\mathrm{m} \cdot \mathrm{s}^{-1}$ \\
\hline$r_{x, y}$ & Pearson correlation coefficient & - \\
\hline $\mathrm{T}_{\mathrm{amb}}$ & recorded ambient temperature & ${ }^{\circ} \mathrm{C}$ \\
\hline $\mathrm{T}_{\text {module }}$ & temperature of the back side of the photovoltaic module & ${ }^{\circ} \mathrm{C}$ \\
\hline $\mathrm{P}_{\text {module }}$ & instantaneous electric power & $\mathrm{W}$ \\
\hline
\end{tabular}

\section{References}

1. Jastrzębska, G. Ogniwa słoneczne. In Budowa Technologia Zastosowanie; WKiŁ: Warsaw, Poland, 2013.

2. Hafez, A.; Yousef, A.; Harag, N. Solar tracking systems: Technologies and trackers drive types-A review. Renew. Sustain. Energy Rev. 2018, 91, 754-782. [CrossRef]

3. Al-Rousan, N.; Isa, N.A.M.; Desa, M.K.M. Advances in solar photovoltaic tracking systems: A review. Renew. Sustain. Energy Rev. 2018, 82, 2548-2569. [CrossRef]

4. Ramli, M.A.; Twaha, S.; Ishaque, K.; Al-Turki, Y.A. A review on maximum power point tracking for photovoltaic systems with and without shading conditions. Renew. Sustain. Energy Rev. 2017, 67, 144-159. [CrossRef]

5. Amir, A.; Selvaraj, J.; Rahim, N. Study of the MPP tracking algorithms: Focusing the numerical method techniques. Renew. Sustain. Energy Rev. 2016, 62, 350-371. [CrossRef]

6. Rimlifegreentech. Available online: www.rimlifegreentech.com (accessed on 10 January 2017).

7. Titantracker. Available online: www.titantracker.com (accessed on 19 February 2014).

8. Quesada, G.; Guillon, L.; Rousse, D.R.; Mehrtash, M.; Dutil, Y.; Paradis, P.-L. Tracking strategy for photovoltaic solar systems in high latitudes. Energy Convers. Manag. 2015, 103, 147-156. [CrossRef]

9. Trzmiel, G.; Głuchy, D.; Kurz, D. The impact of shading on the exploitation of photovoltaic installations. Renew. Energy 2020, 153, 480-498. [CrossRef]

10. Vieira, R.; Guerra, F.; Vale, M.; Araújo, M. Comparative performance analysis between static solar panels and single-axis tracking system on a hot climate region near to the equator. Renew. Sustain. Energy Rev. 2016, 64, 672-681. [CrossRef]

11. Muhammad, J.Y.; Jimoh, M.T.; Kyari, I.B.; Gele, M.A.; Musa, I. A Review on Solar Tracking System: A Technique of Solar Power Output Enhancement. Eng. Sci. 2019, 4, 1-11. [CrossRef]

12. Frydrychowicz-Jastrzęskka, G.; Bugała, A. Modeling the Distribution of Solar Radiation on a Two-Axis Tracking Plane for Photovoltaic Conversion. Energies 2015, 8, 1025-1041. [CrossRef]

13. Yousif, H. Comparison study between the performance of tracking and fixed solar photovoltaic systems in Malta. In Proceedings of the PV in Europe from PV Technology to Energy Solutions Conference \& Exhibition, ETA-Florence, Rome, Italy, 7-11 October 2002; pp. 1065-1068. 
14. Zsiborács, H.; Baranyai, N.H.; Vincze, A.; Háber, I.; Weihs, P.; Oswald, S.; Gützer, C.; Pintér, G. Changes of Photovoltaic Performance as a Function of Positioning Relative to the Focus Points of a Concentrator PV Module: Case Study. Appl. Sci. 2019, 9, 3392. [CrossRef]

15. Fathabadi, S. Comparative study between two novel sensorless and sensor based dual-axis solar trackers. Sol. Energy 2016, 138, 67-76. [CrossRef]

16. Rustu, E.R.; Senturk, A. Performance comparison of a double-axis sun tracking versus fixed PV system. Sol. Energy 2012, $86,2665-2672$.

17. Nalepa, K.; Neugebauer, M.; Sołowiej, P.; Chmielewski, R. Wykorzystanie mikrokontrolera jednoukładowego do sterowania optymalnym ustawieniem płaszczyzny ogniwa fotowoltaicznego w stosunku do Słońca. Agric. Eng. 2009, 8, 127-132.

18. Kivrak, S.; Gunduzalp, M.; Dincer, F. Theoretical and experimental performance investigation of a two-Axis solar tracker under the climatic condition of Denizli, Turkey. Prz. Elektrotech. 2012, 2, 332-336.

19. Serhan, M.; El-Chaar, L. Two axes sun tracking system: Comparison with a fixed system. In Proceedings of the International Conference on Renewable Energies and Power Quality, Granada, Spain, 23-25 March 2010.

20. Okoye, C.; Abbasoglu, S. Empirical investigation of fixed and dual axis Sun tracking photovoltaic system installations in Turkish Republic of Northern Cyprus. J. Asian Sci. Res. 2013, 3, 440-453.

21. Safan, Y.M.; Shaaban, S.; Abu El-Sebah, M.I. Performance evaluation of a multi-degree of freedom hybrid controlled dual axis solar tracking system. Sol. Energy 2018, 170, 576-585. [CrossRef]

22. Chowdhury, M.E.H.; Khandakar, A.; Hossain, B.; Abouhasera, R. A Low-Cost Closed-Loop Solar Tracking System Based on the Sun Position Algorithm. J. Sens. 2019, 2019, 1-11. [CrossRef]

23. Okoye, C.O.; Bahrami, A.; Atikol, U. Evaluating the solar resource potential on different tracking surfaces in Nigeria. Renew. Sustain. Energy Rev. 2018, 81, 1569-1581. [CrossRef]

24. El-Sebah, M.I.A. A Novel Simplified intelligent Universal PID Controller. In Proceedings of the Conference on New Paradigms in Electronics \& Information Technologies, Alexandria, Egypt, 9-11 October 2011; pp. 1-5.

25. Zhang, Q.-X.; Yu, H.-Y.; Zhang, Q.-Y.; Zhang, Z.-Y.; Shao, C.-H.; Yang, D. A Solar Automatic Tracking System that Generates Power for Lighting Greenhouses. Energies 2015, 8, 7367-7380. [CrossRef]

26. Bentaher, H.; Kaich, H.; Ayadi, N.; Ben Hmouda, M.; Maalej, A.; Lemmer, U. A simple tracking system to monitor solar PV panels. Energy Convers. Manag. 2014, 78, 872-875. [CrossRef]

27. Spencer, D.F. Basic Photovoltaic Principles and Methods; Solar Energy Research Institute: Washington, WA, USA, 1984.

28. Kais, I. A low cost single-Axis sun tracker system using PIC microcontroller. DJES 2012, 5, 65-78.

29. Amin, N.; Yung, W.; Sopian, K. Low cost single axis automated sunlight tracker design for higher PV power yield. In Proceedings of the 2007 World Renewable Energy Conference, Taipei, Taiwan, 30 October-1 November 2007; pp. 137-139.

30. Ponniran, A.; Hashim, A.; Munir, H.A. A design of single axis sun tracking system. In Proceedings of the 20115 th International Power Engineering and Optimization Conference, Shah Alam, Malaysia, 6-7 June 2011; pp. 107-110.

31. Fadil, S.; Capar, A.C.; Caglar, K.; Fadıl, S. Two axis solar tracker design and implementation. In Proceedings of the 2013 8th International Conference on Electrical and Electronics Engineering (ELECO), Bursa, Turkey, 28-30 November 2013 ; pp. 554-557.

32. Barsoum, N. Fabrication of Dual-Axis Solar Tracking Controller Project. Intell. Control. Autom. 2011, 2, 57-68. [CrossRef]

33. Ray, S.K.; Bashar, M.A.; Sayed, F.B. Two Ways of Rotating Freedom Solar Tracker by Using ADC of Microcontroller. Glob. J. Res. Eng. 2013, 12.

34. Mukund, R. Wind and Solar Power Systems: Design, Analysis and Operation; Taylor and Francis: New York, NY, USA, 2006.

35. Chen, F.; Feng, J. Analogue sun sensor based on the optical nonlinear compensation measuring principle. Meas. Sci. Technol. 2007, 18, 2111-2115. [CrossRef]

36. Barsoum, N.; Vasant, P. Simplified solar tracking prototype. Glob. J. Technol. Optim. 2010, 1, $38-45$.

37. Lee, C.; Chou, P.; Chiang, C.; Lin, C. Sun tracking systems: A review. Sensors 2009, 9, 3879-3881. [CrossRef] [PubMed]

38. Berenguel, M.; Rubio, F.; Valverde, A.; Lara, P.; Arahal, M.; Camacho, E.; López, M. An artificial vision-based control system for automatic heliostat positioning offset correction in a central receiver solar power plant. Sol. Energy 2004, 76, 563-575. [CrossRef]

39. Brisha, A.M. Enhancement of Power Generation for PV Systems Using Dynamic Tracking System. Int. J. Electr. Compon. Energy Convers. 2019, 5, 1-5.

40. Sumathi, V.; Jayapragash, R.; Bakshi, A.; Akella, P.K. Solar tracking methods to maximize PV system output-A review of the methods adopted in recent decade. Renew. Sustain. Energy Rev. 2017, 74, 130-138. [CrossRef]

41. Bendib, B.; Belmili, H.; Krim, F. A survey of the most used MPPT methods: Conventional and advanced algorithms applied for photovoltaic systems. Renew. Sustain. Energy Rev. 2015, 45, 637-648. [CrossRef]

42. Macaulay, J.; Zhou, Z. A Fuzzy Logical-Based Variable Step Size P\&O MPPT Algorithm for Photovoltaic System. Energies 2018, 11, 1340. [CrossRef]

43. Lee, H.-S.; Yun, J.-J. Advanced MPPT Algorithm for Distributed Photovoltaic Systems. Energies 2019, 12, 3576. [CrossRef]

44. Du, Y.; Yan, K.; Ren, Z.; Xiao, W. Designing Localized MPPT for PV Systems Using Fuzzy-Weighted Extreme Learning Machine. Energies 2018, 11, 2615. [CrossRef]

45. Enany, M.A.; Farahat, M.A.; Nasr, A. Modeling and evaluation of main maximum power point tracking algorithms for photovoltaics systems. Renew. Sustain. Energy Rev. 2016, 58, 1578-1586. [CrossRef] 
46. Fathabadi, H. Novel high efficient offline sensorless dual-axis solar tracker for using in photovoltaic systems and solar concentrators. Renew. Energy 2016, 95, 485-494. [CrossRef]

47. Er, Z.; Balc1, E. Dual axis solar angle tracking system without any sensor. J. Energy Syst. 2018, 2, 127-136. [CrossRef]

48. Ministry of Infrastructure and Development, Climate Database. Available online: http:/ /www.mir.gov.pl (accessed on 2 February 2016).

49. PQSTAT. Available online: http:/ / www.pqstat.pl (accessed on 15 February 2015). 